\title{
EL DISTINTIVO DE EMPRESA SOCIALMENTE RESPONSABLE (ESR) EN EMPRESAS PYMES 2018-2020
}

THE SOCIALLY RESPONSIBLE COMPANY (ESR) BADGE IN SME COMPANIES 2018-2020.

Alejandra Ballesteros-Aureoles ${ }^{1} *$ (D); José Antonio Tlacuilo-González ${ }^{2}$ (D); Diego Demetrio Gaspar-Sarabio ${ }^{3}$ (D).

1.Universidad Tecnológica de Nezahualcóyotl. México. aureoles71@yahoo.com.mx 2.Universidad Tecnológica de Nezahualcóyotl. México. antoniotlacuilo@gmail.com

3.Universidad Tecnológica de Nezahualcóyotl. México. gasparovmx@gmail.com

*Autor de Correspondencia: Alejandra Ballesteros-Aureoles, correo electrónico:aureoles71@yahoo.com.mx

\section{RESUMEN}

Esta investigación tiene como objetivo conocer el distintivo de Empresa Socialmente Responsable ESR, a través de la opinión de los consumidores y de las empresas Pymes que obtuvieron el distintivo de ESR durante los años 2018, 2019 y 2020. El método que se utilizó se divide en dos partes, en la primera se usó el método de recolección de datos cuantitativo, se diseñó un cuestionario con 23 preguntas, abiertas, dicotómicas, y de respuesta múltiple, con el objetivo de conocer ¿qué tipo de consumidor se consideraban respecto a la revisión de las etiquetas, si observan los logotipos en las etiquetas, si identifican las etiquetas del producto y qué tanto conocían los consumidores sobre el distintivo de ESR? Se envió a la población en general, considerando a los habitantes de la Ciudad de México y del Estado de México, por redes sociales (WhatsApp y Facebook). En la segunda parte se revisaron las empresas Pymes que obtuvieron el distintivo de ESR, durante los años 2018, 2019 y 2020, con las publicaciones realizadas por Centro Mexicano de Filantropía (CEMEFI). Los principales hallazgos son que el $29 \%$ de los consumidores si son muy observadores de las etiquetas, el 69\% dijo conocer el distintivo de ESR. Se revisaron 735 empresas Pymes de los años 2018, 2019 y 2020, donde entre el 35\%, el 41\% y el 56\% respectivamente muestran su distintivo de ESR en su página de Internet. Futuras líneas de investigación, que tamaño de empresas micro, pequeñas y medianas, lo logran obtener, estudios de endomarketing para saber si las empresas cumplen con la RSE.

Palabras clave: Marketing social; marketing de responsabilidad social; mix marketing; etiqueta; empresa socialmente responsable.

Cómo citar:

Ballesteros-Aureoles, Alejandra; José Antonio Tlacuilo-González; Diego Demetrio Gaspar-Sarabio. (2021). EL DISTINTIVO DE EMPRESA SOCIALMENTE RESPONSABLE (ESR) EN EMPRESAS PYMES 2018-2020. Revista de Investigaciones Universidad del Quindio, 33(S1), 174-198. https:// doi.org/10.33975/riuq.vol33nS1.491

Revista de Investigaciones Universidad del Quindío, 33(S1), 174-198; 2021. 


\section{ABSTRACT}

The objective of this research is to know the ESR mark, through the opinion of consumers and SME companies that obtained the ESR mark during the years 2018, 2019 and 2020. The method used is divided into two parts, In the first, the quantitative data collection method was used, a questionnaire with 23 questions, open, dichotomous, and multiple response was designed, with the aim of knowing what type of consumer was considered regarding the review of the labels, if they look at the logos on the labels, if they identify the product labels and how well did consumers know about the ESR mark? It was sent to the general population, considering the inhabitants of Mexico City and the State of Mexico, through social networks (WhatsApp and Facebook). In the second part, the SMEs that obtained the ESR distinctive were reviewed, during the years 2018, 2019 and 2020, with the publications made by the Mexican Center for Philanthropy (CEMEFI). The main findings are that 29\% of consumers are very observant of labels, 69\% said they know the ESR badge. 735 SME companies from the years 2018, 2019 and 2020 were reviewed, where between $35 \%, 41 \%$ and $56 \%$ respectively show their ESR badge on their Internet page. Future lines of research, which size of micro, small and medium-sized companies are able to obtain, endomarketing studies to find out if companies comply with CSR.

Keywords: Social Marketing; Social Responsibility Marketing; Marketing Mix; Label; Socially Responsible Company.

\section{INTRODUCCIÓN}

El trabajo se divide en cuatro secciones, la primera es la introducción, la segunda el marco teórico, la tercera el método, en la cuarta están los principales hallazgos, las conclusiones y las líneas de investigación futuras. Se inicio con el resumen, cinco palabras clave, se cierra con la lista de referencias que se consultaron.

En la sección del marco teórico, se revisan los conceptos de Marketing social, Marketing de Responsabilidad Social, Mix marketing, Etiqueta, Empresa Socialmente Responsable. Autores como Kotler (2018), AMA (2018), utilizan el término Marketing, mientras que, en México, Fischer (2017), Saldaña (1999), Saldaña \& Cervantes (2000), utilizan la palabra Mercadotecnia.

Para el caso de la diferencia entre marketing y responsabilidad sociales, se menciona al Marketing Social que depende generalmente sólo del área de Marketing, la RSE, si bien puede tener un departamento propio, atañe a toda la compañía, mientras que una campaña de Marketing Social está enfocada a consumidores; la RSE está enfocada a stakeholders o grupos de interés, finalmente el Marketing Social es una táctica. Responsabilidad Social es la estrategia. (Maram, 2011)

Otro concepto es el de Mix Marketing, Mezcla del Marketing, Mezcla de la Mercadotecnia, o las 4 p's, 5 p's, usado indistintamente y formado por el producto, el precio, la plaza, la promoción y el servicio postventa. Dentro del producto se revisan las 4 e's del producto, el envase, el empaque, el embalaje y la etiqueta, de esta última e, se revisan los elementos de una etiqueta y se revisa el distintivo de Empresa Socialmente Responsable (ESR).

Respecto al método, este se realiza en dos partes, en la primera se usó el método de recolección de datos cuantitativo (Sampieri, Méndez, \& Mendoza, 2017), se diseñó un cuestionario elaborado 
con el software de Microsoft Forms, con 23 preguntas, 3 abiertas, 10 dicotómicas, 10 de respuesta múltiple, con el objetivo de conocer ¿qué tipo de consumidor se consideraban respecto a la revisión de las etiquetas, si veían los logotipos en las etiquetas, si identificaban y qué tanto conocían sobre el distintivo de ESR. Se envió a la población en general, considerando a la ciudad de México y al Estado de México se envió por redes sociales como WhatsApp y Facebook del 11 a 18 de enero de 2021.

Con los siguientes datos estadísticos y la fórmula para el cálculo de la muestra para poblaciones infinitas, considerando 9,209,944 habitantes en la Ciudad de México, para el año 2020 y 16, 992, 418 habitantes en el Estado de México. (INEGI, 2021); con un nivel de confianza del 87\%, una probabilidad a favor del $6 \%$ y un error del $7 \%$.

En la segunda parte se revisaron las empresas Pymes que obtuvieron el distintivo de ESR, durante los años 2018, 2019 y 2020, publicados por CEMEFI. Al final se presentan los principales hallazgos, las conclusiones y las líneas de investigación futuras.

El objetivo general de este trabajo conocer el distintivo de ESR, a través de la opinión de los consumidores y de las empresas Pymes que obtuvieron el distintivo de ESR durante los años 2018, 2019 y 2020 y se plantearon tres preguntas de investigación

\section{MARCO TEÓRICO}

En este apartado se definen los conceptos de Mercadotecnia o Marketing, la diferencia entre Marketing social y Marketing de Responsabilidad Social, el Mix marketing, específicamente el producto, para hablar de las 4 e's y definir a la Etiqueta, para conocer sus elementos de ésta y entonces hablar del distintivo de Empresa Socialmente Responsable (ESR) y de la Responsabilidad Social Empresarial (RSE).

\section{Marketing o Mercadotecnia}

Para una revisión del concepto de Marketing, se considera usar el concepto de Marketing y Mercadotecnia de manera indistinta; como una traducción de Marketing, la palabra Mercadotecnia. Para autores como Kotler (2018), AMA (2018), utilizan el término Marketing, mientras que, en México, Fischer (2017), Saldaña (1999), Saldaña \& Cervantes (2000), utilizan la palabra Mercadotecnia.

Cada autor tiene su propia definición se menciona a Kotler y Keller (2006), citado por Bur (2014), el Marketing constituye una disciplina integradora, proactiva, orientada a la satisfacción de las necesidades de públicos objetivos o targets. Por lo que la finalidad del Marketing es obtener beneficios mutuos, satisfacción de las necesidades de un público objetivo y beneficios para la organización. Las organizaciones buscan satisfacer las necesidades de los consumidores presentando una propuesta de valor que se concreta en una oferta de bienes o servicios.

Mientras que la American Marketing Association (1985), quien da una de las definiciones más precisas, define al Marketing como un conjunto de procesos para crear, comunicar y entregar valor a los clientes y administrar las relaciones con los clientes, de manera que beneficien a la organización y a sus accionistas. 


\section{Marketing Social vs Marketing de Responsabilidad Social}

Diferencia entre Marketing Social y Responsabilidad Social, si bien ambos conceptos están fuertemente entrelazados, existen algunas diferencias entre ellas. El Marketing Social es nombrado por primera vez en 1971 por Gerald Zaltman y Philip Kotler en el Artículo Social Marketing: an Approach to Planned Social Change; en cuanto al Marketing de Responsabilidad Social, es en el siglo XIX que algunos empresarios industriales en Europa y en los EE. UU. se preocupaban por la vivienda, el bienestar y la caridad de sus empleados. Aunque se dice que es hasta los 90as. cuando en Europa, la Comisión Europea para implicar a los empresarios en una estrategia de empleo que generase mayor cohesión social, utilizó el concepto. (FCEE, 2014).

El Marketing Social nace en el seno de las Organizaciones No Gubernamentales (ONG) y las campañas gubernamentales para intentar cambiar actitudes sociales respecto de problemas como alcoholismo, planificación familiar, etc. Mientras el Marketing de Responsabilidad Social, es un concepto empresarial por definición. La Responsabilidad Social está alineada al desarrollo sustentable por lo que responde a las 3 P's: People, Planet, Profit. El marketing social por su parte también responde a las P's, pero a las cuatro, Product, Price, Place, Promotion, y en el caso de los servicios se agregan otras 3, People, Process, Physical Evidence. (FCEE, 2014)

Cuando se ejecuta marketing social, se cruzan las P's del marketing con las de la sustentabilidad. El Marketing Social es la serie de actividades que tiene por objeto la modificación de opiniones, actitudes o comportamientos por parte de ciertos públicos con el objeto de mejorar alguna situación social y/o medioambiental. (FCEE, 2014)

La Responsabilidad Social se podría definir como la estrategia de gestión empresarial a través de la cual las compañías toman decisiones teniendo en cuenta la rentabilidad, la sociedad y el medio ambiente. El Marketing Social es una táctica ejecutada en forma y tiempo determinados, aplicada a un segmento definido bajo objetivos empresariales donde la rentabilidad juega un papel fundamental. (FCEE, 2014)

Una empresa que ejecuta Marketing Social no necesariamente es socialmente responsable; sin embargo, una empresa socialmente responsable, generalmente ejecuta alguna campaña de Marketing Social. La Responsabilidad Social es una estrategia permanente transversal a todas las áreas de una organización y enfocada a stakeholders. El Marketing Social puede ser parte de la estrategia de responsabilidad social; esta situación nunca se dará en sentido inverso. (FCEE, 2014)

Se identifican seis dimensiones de la responsabilidad social que el consumidor espera del marketing de las empresas: Calidad de los bienes y servicios, calidad del servicio al cliente, publicidad y prácticas de promoción, información al consumidor, respeto por la privacidad del consumidor, ética y compromiso social. (EXPONEWS, 2010)

Las empresas y organizaciones para desarrollar estrategias y tácticas de marketing y ventas socialmente responsables atendiendo a las demandas externas de los consumidores y grupos de interés, deben tener en cuenta la dimensión interna de la Responsabilidad Social. Ésta abarca a toda la organización y no se limita al mero cumplimiento de cuestiones legales. 
Los principios fundamentales para considerar para fortalecerla internamente son: • En el plano laboral. - En el plano ambiental, conciliar la vida laboral con la familiar. • En el plano empleabilidad y gestión del cambio. • Formación del personal para brindar flexibilidad laboral, es decir que el empleado pueda ser útil en varias áreas de la organización. - Capacitación continua para adaptarse a la evolución permanente del sistema. - Planes de desarrollo individualizados. • Planes de desarrollo directivos, favoreciendo la motivación y aumentando la productividad. (Stanley, 2021)

Finalmente, el marketing social, por su parte, es la serie de actividades de marketing que busca la modificación de opiniones, actitudes o comportamientos de ciertos públicos, con el objeto de mejorar alguna situación social y/o medioambiental. La forma más común del marketing social es el marketing con causa, donde la empresa apoya a una causa social o ambiental a través de donar una parte de la venta de sus productos. Sin embargo, las compañías también pueden hacer marketing social al sólo generar conciencia; al hacer inversión social (anteriormente llamada filantropía estratégica) o a través de desarrollar productos o servicios virtuosos que ayuden a la sociedad y al medio ambiente. (Maram, 2011)

Existen tres puntos cruciales que marcan la diferencia entre marketing y responsabilidad sociales: (Maram, 2011)

1) Marketing Social depende generalmente sólo del área de Marketing. La RSE, si bien puede tener un departamento propio, atañe a toda la compañía.

2) Una campaña de Marketing Social está enfocada a consumidores; la RSE está enfocada a stakeholders o grupos de interés.

3) Marketing Social es una táctica. Responsabilidad Social es la estrategia.

\section{Mix Marketing}

El Mix Marketing, Mezcla del Marketing, Mezcla de la Mercadotecnia, o las 4 p's, 5 p's. autores como Jerome Mc Carthy, Neil Borden, Dick Berry y Robert Lauterborn. La mezcla de marketing es el conjunto de herramientas, tácticas de marketing (producto, precio, plaza y promoción, que la empresa combina para producir la respuesta deseada en el mercado meta. (Kotler, 2017). Esto lo podemos ver en la imagen siguiente. 
Imagen 1. Mix Marketing $=$ Mezcla de la Mercadotecnia $=4$ p's (producto, precio, plaza, promoción)

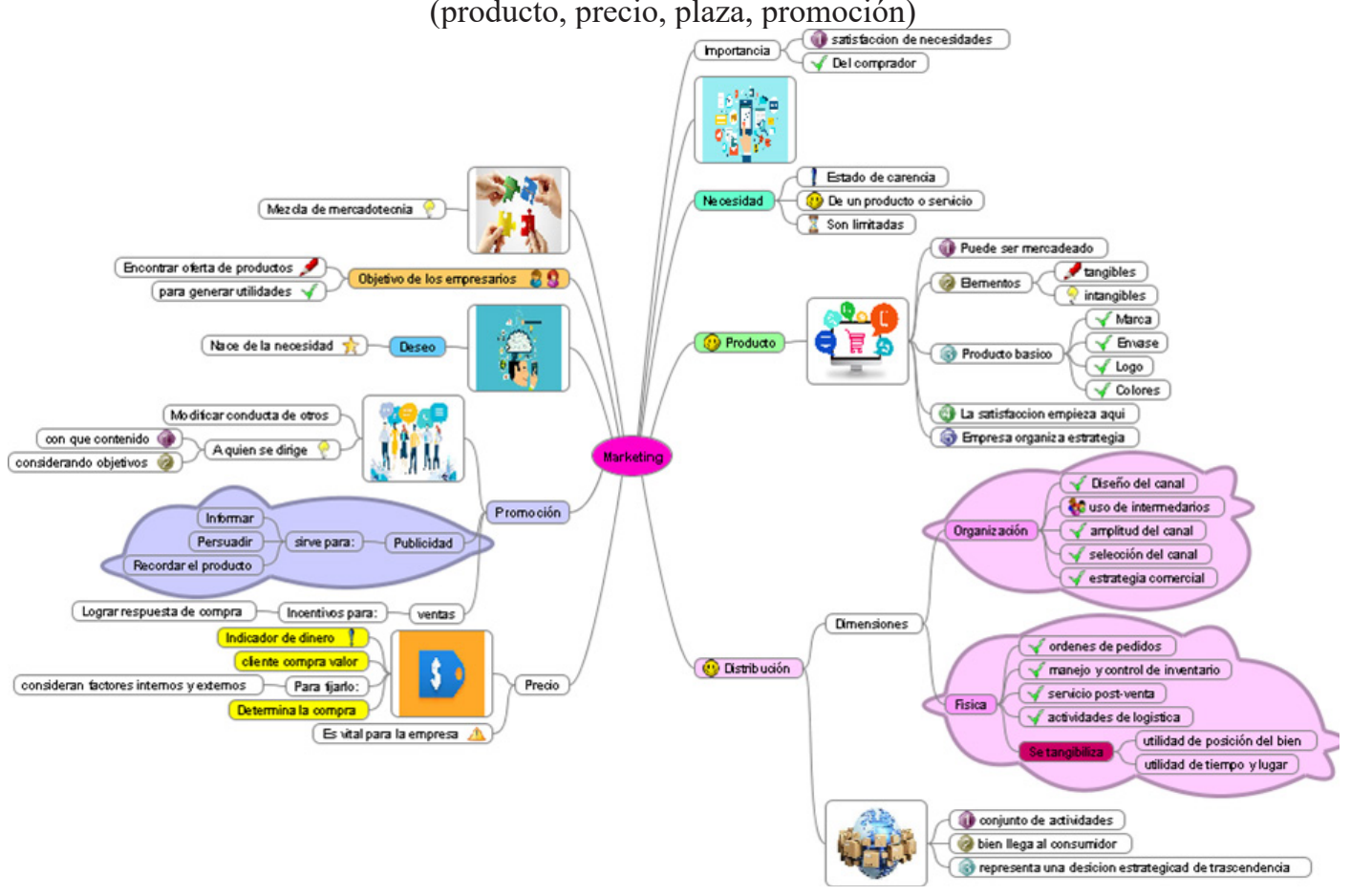

Fuente: elaborado por Guadalupe González Olvera con datos de (Peñaloza, 2005).

De los elementos de la Mezcla de la Mercadotecnia o 4 p's, encontramos al producto, el cual se define como todo aquello que puede ofrecerse a un mercado para su uso o consumo y que, además, puede satisfacer un deseo o necesidad. Abarca objetos físicos, servicios, personas, sitios, organizaciones e ideas. (Kotler, 2017).

Dentro de los elementos del producto, se definen a las 4 e's, formados por el envase, el empaque, el embalaje y la etiqueta.

Imagen 2. Las 4 e's

\section{ELEMENTOS DEL PRODUCTO, LAS 4 e's:}

\section{ENVASE \\ EMPAQUE \\ EMBALAJE \\ ETIQUETA}

Fuente: Elaboración propia

\section{La Etiqueta (el cuarto elemento de las 4 e's)}

Según la Real Academia Española, se define como un marbete o etiqueta, aquella que se adhiere a algún objeto, ya sea en piezas de tela, cajas, botellas, frascos u otros objetos, donde se suele 
manuscribir o imprimir la marca de fábrica o expresar un rótulo de lo que se contienen dentro, a veces son sus cualidades, uso, precio, entre otros. La etiqueta es una pieza de papel, cartón, u otro material, generalmente rectangular, que se coloca en un objeto o mercancía para su identificación. (RAE, 2021).

La etiqueta o rótulo entrega información útil y relevante sobre la empresa o emprendimiento y las características o atributos propios del producto. (Alimentos, 2021).

Según la NOM-050-SCFI-2004, una etiqueta debe incluir información comercial básica que permita a los consumidores saber cuál es el contenido, qué ingredientes tiene, etc. En la imagen 3 se muestra una infografía donde se pueden consultar los elementos que según esta norma deben incluir todas las etiquetas de productos de origen nacional o internacional. (NOM, 2004).

Imagen 3. Infografía Normas de etiquetado de un producto. NOM-050-SCFI-2004.

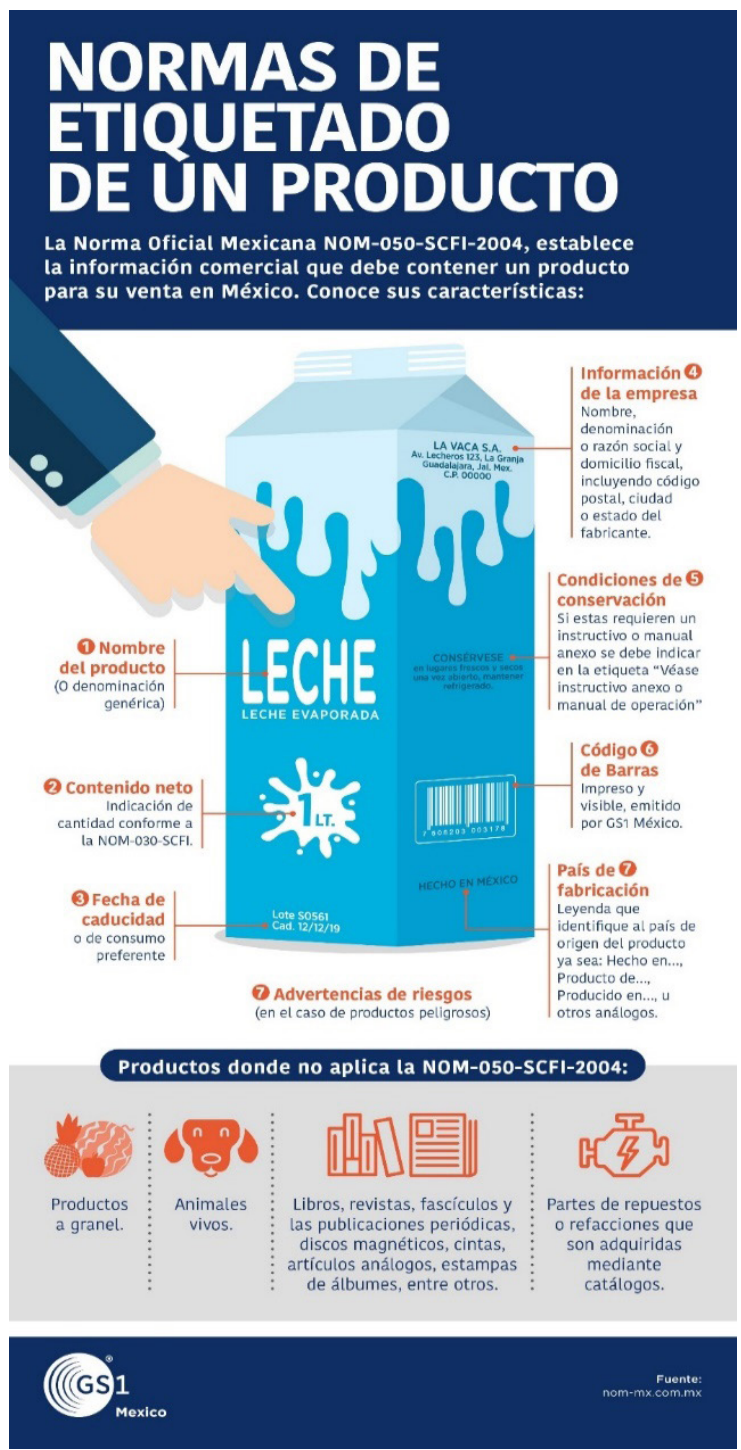

Fuente: https://unejemplosencillo.blogspot.com/2019/01/ ejemplo-de-etiqueta-nom-050-scfi-2004.html

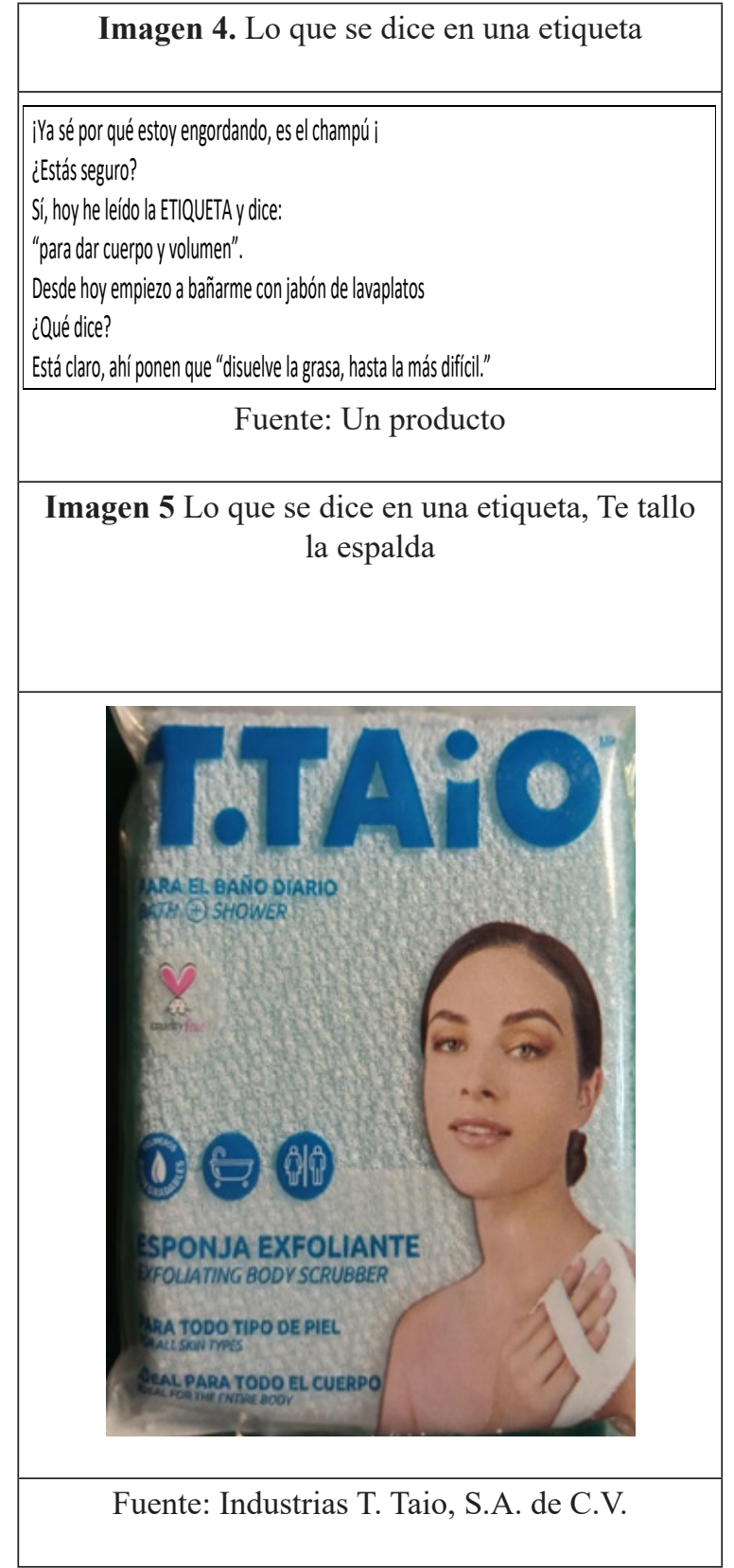


En la imagen 6 se muestran 30 elementos de una etiqueta.

1. El logo de la empresa

2. Nombre del producto

3. Contenido Neto

4. Código de barras

5. Ingredientes

6. Tabla nutricional

7. Fecha de elaboración

8. Fecha de caducidad

9. Lema de la empresa

10. Nombre de la empresa

11. Empresa responsable

12. Lugar de fabricación

Imagen 6. Elementos de la etiqueta

13. Lote de fabricación

14. Instrucciones de conservación

15. Indicación de contenido efectivo

16. Denominación de venta

17. Tamaño de la porción

18. Identificación de la empresa

19. País de origen

20. Permiso del ministerio de salud

21. Teléfono o contacto de la empresa

22. Dirección de la empresa

23. Campaña social

24. Propaganda

25. Color

26. Fuentes de elaboración

27. Información nutricional

28. Imagen

29. Logo de reciclaje

30. Producto líder
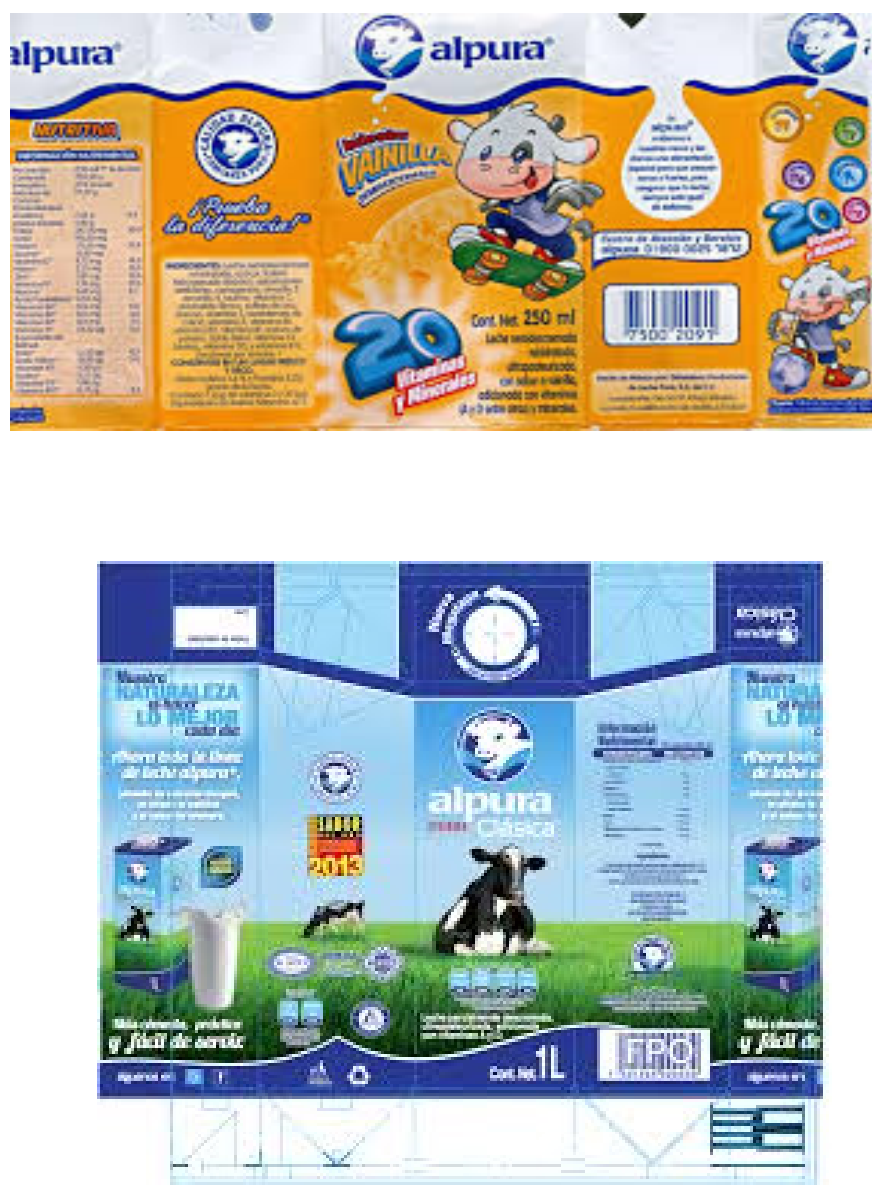

Fuente: Elaboración propia con datos de Alpura. El poder de la leche. https://alpura.com/

Algunas de las iniciativas más representativas de responsabilidad social a nivel global son El Pacto Mundial (organización de la ONU que promueve comportamientos responsables de las empresas); la Global Reporting Initiative (que desarrolla guías para elaborar memorias de sostenibilidad); la ISO26000 (guía ISO que establece líneas en materia de RS para organizaciones); las directrices de la OCDE (recomendaciones dirigidas por los gobiernos a las empresas multinacionales), entre muchas otras. (Maram, 2011)

El ejercicio de una empresa socialmente responsable, recientemente se ha convertido en una nueva forma de gestión y de hacer negocios, en la cual la empresa se ocupa de que sus operaciones sean sustentables en lo económico, en lo social y en lo ambiental, es una visión de negocios que integra el respeto por las personas, los valores éticos, la comunidad y el medioambiente con la gestión misma de la empresa, independientemente de los productos o servicios que ésta ofrece, del sector al que pertenece, de su tamaño o nacionalidad. (CEMEFI, 2018).

LaResponsabilidad SocialEmpresarial consiste en un comportamiento que es adoptado voluntariamente, por las empresas, mejorando la calidad de vida de las personas y sus familias, beneficios que redundan a largo plazo en su propio interés, dice Bonilla (2009), mencionado por Fischer (2017). 
En los orígenes de la RSE en México habrá que ubicarse hacia mediados del siglo XX. Dos organizaciones empresariales destacaron por su insistencia y pronunciamiento en el tema: la Confederación Patronal de la República Mexicana (Coparmex) y, en ese entonces la Organización Uniones Sociales de Empresarios de México, A.C. (USEM). Ambas aportaron elementos teóricoprácticos para la fundamentación y desarrollo del concepto mismo (Bonilla, 2009), mencionado por Fischer (2017).

En 1992, el Centro Mexicano para la Filantropía(CEMEFI), creó el programa de Filantropía Empresarial con seis empresas participantes, desde esa fecha se habla de Empresas Socialmente Responsables y Responsabilidad Social Empresarial. Ahora existen en México diferentes organismos que dictan los lineamientos a seguir en materia de RSE, ya sea de forma directa o indirecta, se mencionan los siguientes: (Fischer F. , 2017).

$\checkmark$ CEMEFI (Centro Mexicano de la Filantropía)

$\checkmark$ Aliarse (Alianza para la Responsabilidad Social Empresarial)

$\checkmark$ Concamin

$\checkmark$ Comdes (Consejo Mexicano para el Desarrollo Económico y Social)

$\checkmark$ CCE (Consejo Coordinador Empresarial)

$\checkmark$ Coparmex (Confederación Patronal de la República Mexicana)

$\checkmark$ Confederación USEM (Unión Social de Empresarios de México)

$\checkmark$ Desem (Desarrollo Empresarial Mexicano).

\section{Centro Mexicano de la Filantropía (CEMEFI)}

CEMEFI, es una asociación civil fundada en diciembre de 1988. CEMEFI, es una institución privada, no lucrativa, sin ninguna filiación a partido, raza o religión. Cuenta con la autorización del Gobierno de México para recibir donativos deducibles de impuestos. Su sede se encuentra en la Ciudad de México y su ámbito de acción abarca todo el país. (CEMEFI, 2018).

La misión de CEMEFI (2016), es promover y articular la participación filantrópica, comprometida para alcanzar una sociedad más equitativa, solidaria y próspera. En lo referente a la Responsabilidad Social Empresarial, realiza acciones como aplicar un proceso diagnóstico para la obtención del Distintivo ESR, mejores prácticas en SER, cursos, talleres y seminarios.

\section{Distintivo ESR}

El Centro Mexicano para la Filantropía (Cemefi) y la Alianza por la Responsabilidad Social Empresarial (AliaRSE), cada año hacen público el listado de las empresas que obtienen el Distintivo ESR ${ }^{\circledR}$, las cuales cumplieron satisfactoriamente con los estándares establecidos en los ámbitos de la RSE. Reconociendo el esfuerzo por asumir voluntaria y públicamente el compromiso de implementar una gestión socialmente responsable y de mejora continua, como parte de su cultura y estrategia de negocio. Se exhorta a las empresas a seguir fortaleciendo acciones socialmente responsables, para la construcción del bien común. (CEMEFI, 2018). 
En la siguiente imagen se muestra el distintivo de ESR por más de 30 años.

Imagen 7. Distintivo de Empresa Socialmente Responsable (ESR)

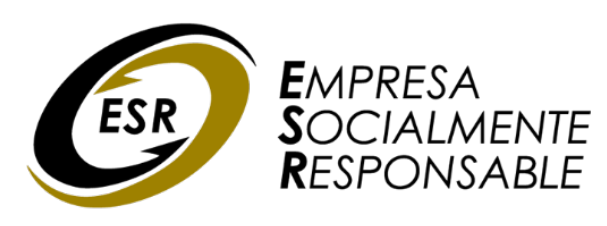

Fuente: Empresa Socialmente Responsable (cemefi.org). https://www.cemefi.org/esr/index.php

\section{Responsabilidad Social Empresarial (RSE)}

La responsabilidad social empresarial (RSE) es la integración voluntaria, por parte de las compañías, de las preocupaciones sociales y ambientales en sus operaciones comerciales y en sus relaciones con sus interlocutores. En esta definición, realizada por la Comunidad Europea, podemos apreciar que la RSE no se limita a una acción de marketing, sino que atañe a todas las áreas y departamentos de una organización, desarrollándose de manera transversal a través de ésta. (Maram, 2011)

RSE, es el compromiso consciente y congruente de cumplir integralmente con la finalidad de la empresa, tanto en lo interno como en lo externo, considerando las expectativas económicas, sociales y ambientales de todos sus participantes, demostrando respeto por la gente, los valores éticos, la comunidad y el medio ambiente, contribuyendo así a la construcción del bien común. (CEMEFI, 2019)

La dimensión integral de la Responsabilidad Social Empresarial: dimensión económica interna, dimensión económica externa, dimensión social interna, dimensión sociocultural y política externa, dimensión ecológica interna y dimensión ecológica externa. (CEMEFI, 2019)

Las Líneas estratégicas son: • Ética y gobernabilidad empresarial. • Calidad de vida en la empresa (dimensión social del trabajo). • Vinculación y compromiso con la comunidad y su desarrollo. • Cuidado y preservación del medioambiente. (CEMEFI, 2019)

Principios de la Responsabilidad Social Empresarial: Respeto a la dignidad de la persona, Empleo digno. Solidaridad. Subsidiariedad. Contribución al bien común. Corresponsabilidad. Confianza. Ética en los negocios. Prevención de negocios ilícitos. Vinculación con la comunidad. Transparencia. Honestidad y legalidad. Justicia y equidad. Empresarialidad. Desarrollo social. (CEMEFI, 2019)

\section{MÉTODO}

Este trabajo se realizó en dos partes, en la primera se usó el método de recolección de datos cuantitativo (Sampieri, Méndez, \& Mendoza, 2017), se diseñó un cuestionario elaborado con el software de Microsoft Forms, con 23 preguntas, 3 abiertas, 10 dicotómicas, 10 de respuesta múltiple, con el objetivo de conocer ¿qué tipo de consumidor se consideraban respecto a la revisión de las etiquetas, si observan los logotipos en las etiquetas, si identificaban y qué tanto conocían sobre el distintivo de ESR?. Se usó el método de muestreo probabilístico, el aleatorio simple (Aaker \& Kumar, 2010), se envió a la población en general, considerando una población dela ciudad de México y el Estado de México, considerando los contactos que se tienen en las redes sociales (WhatsApp y Facebook), 
se envió del 11 a 18 de enero de 2021, solamente una pregunta sirvió para conocer el perfil del consumidor, solicitando su lugar de residencia.

Con los siguientes datos estadísticos y la fórmula para el cálculo de la muestra para poblaciones infinitas, considerando 9,209,944 habitantes en la Ciudad de México, para el año 2020 y 16, 992, 418 habitantes en el Estado de México. (INEGI, 2021); con un nivel de confianza del 87\%, una probabilidad a favor del $6 \%$ y un error del $7 \%$.

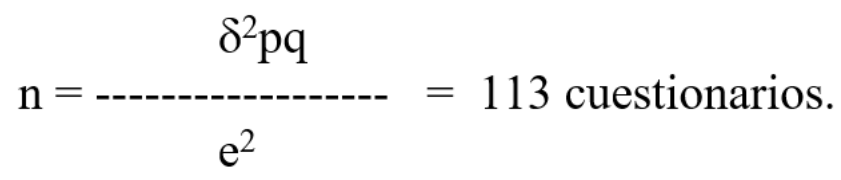

Imagen 8. Diseño de cuestionario

\begin{tabular}{|c|c|c|c|c|c|c|c|c|c|}
\hline 1 & $\begin{array}{l}\text { ¿Se considera un consumidor que lee, revisa, } \\
\text { observa las etiquetas de los productos? }\end{array}$ & a) Sí, muy observador & $\begin{array}{l}\text { b) Sí, sólo en algunos } \\
\text { productos como } \\
\text { alimentos }\end{array}$ & c) Sí, a veces & d) No & e) Nunca & & & \\
\hline 2 & ¿Conoce el logotipo de ESR? & a) sí & b) no & & & & & & \\
\hline 3 & ¿Qué significa? & ABIERTA & & & & & & & \\
\hline 4 & $\begin{array}{l}\text { ¿Considera que es importante que todos } \\
\text { conozcan el significado del ESR? }\end{array}$ & a) sí & b) no & & & & & & \\
\hline 5 & $\begin{array}{l}\text { ¿Sabe quién de las siguientes instituciones, } \\
\text { comisiones, empresas organizaciones otorga el } \\
\text { logotipo de ESR? }\end{array}$ & a) EEMEFI & $\begin{array}{l}\text { b)SECRETARIA DE } \\
\text { ECONOMÍA }\end{array}$ & $\begin{array}{l}\text { c) SECRETARIA DEL } \\
\text { MEDIO AMBIENTE }\end{array}$ & d) UNAM & & & & \\
\hline 6 & $\begin{array}{l}\text { ¿Consideras que todas las empresas pueden } \\
\text { obtener el logotipo ESR? }\end{array}$ & $\begin{array}{l}\text { a) si, ya que agrega } \\
\text { valor a la marca y } \\
\text { rentabilidad }\end{array}$ & b) no & c) desconozco el tema & & & & & \\
\hline 7 & $\begin{array}{l}\text { ¿Sabe para qué sirve a las empresas obtener el } \\
\text { logotipo de ESR? }\end{array}$ & $\begin{array}{l}\text { a) Cuidar el medio } \\
\text { ambiente; }\end{array}$ & $\begin{array}{l}\text { b) Porque es una } \\
\text { empresa socialmente } \\
\text { responsable; }\end{array}$ & $\begin{array}{l}\text { c) Por hacer } \\
\text { mercadotecnia social; }\end{array}$ & \begin{tabular}{|l|} 
d) Por hacer \\
mercadotecnia para la \\
responsabilidad social;
\end{tabular} & \begin{tabular}{|l|} 
e) Por hacer \\
mercadotecnia \\
sustentable;
\end{tabular} & & & \\
\hline 8 & $\begin{array}{l}\text { ¿ Recuerda haber visto este logotipo en alguno } \\
\text { (s) de los siguientes productos y /o servicios, } \\
\text { marque todos los que recuerde? }\end{array}$ & a) PEÑAFIEL & b) TANG & c) PINOL & d) SALSA HUNT & e) CINÉPOLIS & f) TELMEX & g) MAZAPANES & h) SUEROX \\
\hline 9 & $\begin{array}{l}\text { ¿Por qué piensas que algunas marcas no tienen el } \\
\text { distintivo ESR? }\end{array}$ & a) no les interesa; & $\begin{array}{l}\text { b) no cumplen con la } \\
\text { responsabilidad social, } \\
\text { no cumplen con la ley y } \\
\text { no generan valores; }\end{array}$ & $\begin{array}{l}\text { c) les sale muy caro } \\
\text { obtener el distintivo; }\end{array}$ & & & & & \\
\hline 10 & $\begin{array}{l}\text { ¿Conoces algunas de las } 5 \text { reglas de uso } \\
\text { relevantes del logotipo ESR? }\end{array}$ & a) sí & b) no & & & & & & \\
\hline 11 & Menciona 2 reglas: & ABIERTA & & & & & & & \\
\hline 12 & $\begin{array}{l}\text { ¿Consideras que es importante que las empresas } \\
\text { obtengan el distintivo ESR? }\end{array}$ & a) sí & b) no & & & & & & \\
\hline 13 & ¿Por qué? & ABIERTA & & & & & & & \\
\hline 14 & $\begin{array}{l}\text { ¿Estarías dispuesto a pagar más por una marca } \\
\text { socialmente responsable? }\end{array}$ & a) sí & b) no & & & & & & \\
\hline 15 & $\begin{array}{l}\text { ¿Estas informado sobre cada cuanto tiempo de } \\
\text { otorga el distintivo ESR por CEMEFI y aliarse en } \\
\text { México? }\end{array}$ & a) sí & b) no & & & & & & \\
\hline 16 & $\begin{array}{l}\text { ¿Consideras que cada año las empresas se } \\
\text { actualicen con el distintivo ESR? }\end{array}$ & $\begin{array}{l}\text { a) Sí, hablan de su } \\
\text { responsabilidad con la } \\
\text { sociedad; }\end{array}$ & $\begin{array}{l}\text { b) No, con una lo } \\
\text { actualicen una vez; }\end{array}$ & $\begin{array}{l}\text { c) No sabia que lo } \\
\text { actualizaban cada año }\end{array}$ & d) Desconozco del tema & & & & \\
\hline 17 & $\begin{array}{l}\text { ¿Has consumido productos del grupo peñafiel y } \\
\text { has notado que tiene el distintivo ESR? }\end{array}$ & a) sí & b) no & & & & & & \\
\hline 18 & $\begin{array}{l}\text { ¿Has visto que la marca de la Rosa se actualice } \\
\text { cada año con el distintivo ESR? }\end{array}$ & a) sí & b) no & & & & & & \\
\hline 19 & $\begin{array}{l}\text { ¿Qué productos de la empresa del monte has } \\
\text { consumido que tenga el distintivo ESR? }\end{array}$ & a) Cátsup & b) Néctar de frutas & c) Te frío & d) Verdura en lata & & & & \\
\hline 20 & $\begin{array}{l}\text { ¿Consideras que la marca baby Mink se preocupe } \\
\text { por ser una Empresa Socialmente Responsable? }\end{array}$ & \begin{tabular}{|l|} 
a) sí, telas son \\
sustentables, \\
renovables, \\
biodegradables e \\
hipoalergénicas \\
\end{tabular} & $\begin{array}{l}\text { b) no, sus productos } \\
\text { tienen químicos tóxicos } \\
\text { que dañan al planeta }\end{array}$ & & & & & & \\
\hline 21 & $\begin{array}{l}\text { ¿En cuáles de los siguientes productos has } \\
\text { notado o visto el logo de Empresas Socialmente } \\
\text { Responsables ESR? }\end{array}$ & a) Refresco peñafiel & b) Pinol & c)Galletas Gamesa & d) Chocomilk & e) Todas & & & \\
\hline 22 & $\begin{array}{l}\text { ¿Consideras que este cuestionario te ayudo para } \\
\text { saber un poco sobre el distintivo ESR? }\end{array}$ & a) sí & b) no & c) Tal vez & & & & & \\
\hline 23 & ¿ Cuál es tú Municipio o Alcandía donde vives? & ABIERTA & & & & & & & \\
\hline
\end{tabular}

Fuente: Elaboración propia, 
En la segunda parte, se consultaron los informes que publica CEMEFI, donde se dice a la letra: "El Centro Mexicano para la Filantropía, A.C. (CEMEFI) y la Alianza por la Responsabilidad Social Empresarial (AliaRSE) se complacen en anunciar el nombre de las empresas que este año cumplieron con los estándares para alcanzar el Distintivo ESR®”, (CEMEFI, 2018, 2019, 2020), en este trabajo, para los años 2018, 2019 y 2020, exclusivamente para empresas de tamaño Pymes.

Para obtener la información específica de las empresas se consultaron las páginas en Internet de cada una de las empresas, y también se realizó una búsqueda en la página de MexicoPymes - Directorio de Empresas y Negocios de México en: https://mexicopymes.com/

También se buscaron para esos mismos años, las entidades u organismos promotores de la Responsabilidad Social Empresarial (RSE), y cuáles son los requerimientos para obtener ese distintivo.

Se escribe un objetivo general y tres preguntas de investigación.

\section{Objetivo general}

Conocer el distintivo de ESR, a través de la opinión de los consumidores y de las empresas Pymes que obtuvieron el distintivo de ESR durante los años 2018, 2019 y 2020.

\section{Preguntas de investigación}

1. ¿Cuáles son las posibles diferencias entre Marketing Social y Marketing de Responsabilidad Social?

2. ¿Qué sabe el Consumidor sobre los elementos de la etiqueta y el distintivo ESR?

3. ¿Qué características tienen las empresas que han logrado obtener el distintivo de ESR por primera vez durante los años 2018, 2019 y $2020 ?$

\section{Hallazgos}

\section{Encuesta dirigida a la población en general}

En las siguientes cinco gráficas y la tabla 1, están los resultados de algunas de respuestas del cuestionario que se aplicó a la población siendo residentes de los municipios del Estado de México: $56 \%$ de Nezahualcóyotl, 22\% de Chimalhuacán, 4\% de Ixtapaluca, 2\% de Valle de Chalco y 2\% en Ecatepec, de la Ciudad de México están las alcaldías de Álvaro Obregón 1\%, Coyoacán 1\% e Iztapalapa 6\%.

A la pregunta respecto a ¿qué tipo de consumidor se consideraban, que, si leían, revisaban o solamente observaban las etiquetas?, respondieron, el $29 \%$ qué si eran muy observadores, el $37 \%$ que a veces, el $22 \%$ que sí lo hacían, pero solamente para productos alimenticios, el $8 \%$ que no lo hacía y el 2\% que no o nunca.

A la pregunta ¿conoce el distintivo de ESR?, el 69\% dijo que sí, que significa que es una Empresa Socialmente Responsable, que trabaja apegada a valores y que dentro de sus objetivos empresariales incluye apoyar en necesidades sociales, el 24\% mencionó que no lo conocía, no lo sabía o no lo 
recordaba, el 1\% mencionó que se refería al cuidado del medio ambiente y otro 1\% mencionó que se refería a un producto de calidad.

Imagen 9. Residencia de la población

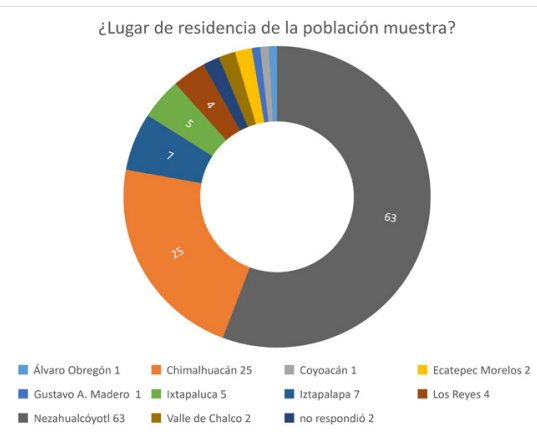

Fuente: Elaboración propia. México. Marzo, 2021.

Imagen 11. Conoce el logotipo de ESR

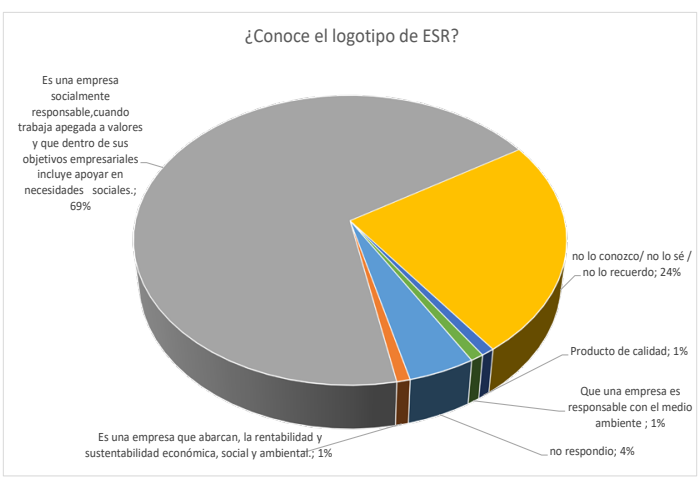

Fuente: Elaboración propia. México. Marzo, 2021.
Imagen 10. ¿Qué tipo de consumidor se consideraban, que, si leían, revisaban o solamente observaban las etiquetas?

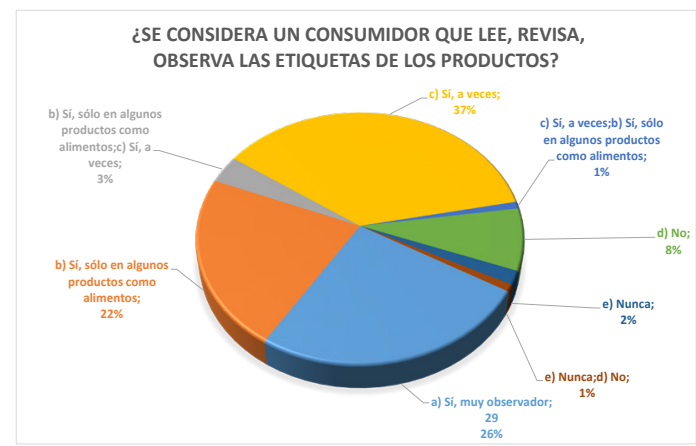

Fuente: Elaboración propia. México. Marzo, 2021.

Imagen 12. Qué institución otorga el distintivo de ESR

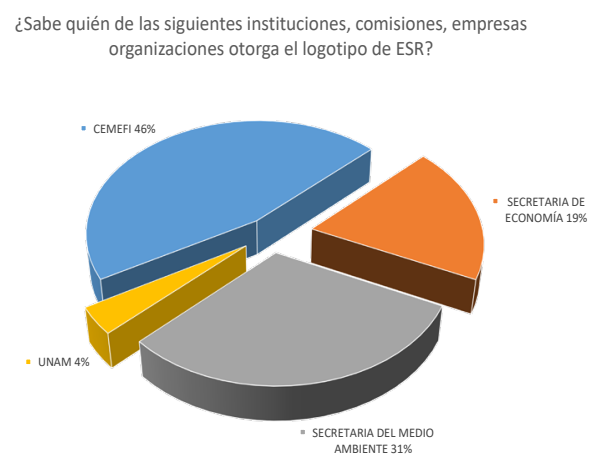

Fuente: Elaboración propia. México. Marzo, 2021.

A la pregunta ¿quién otorga el distintivo de ESR?, el 46\% mencionó que CEMEFI, 19\% la Secretaría de Economía, el 31\% la Secretaría del Medio Ambiente y el 4\% la UNAM.

A la pregunta que, ¿recuerda haber visto el distintivo de ESR en algunos de los siguientes productos? el 26\% dijo que en la marca PEÑAFIEL, el 9\% en TANG, el 16\% en PINOL, el 11\% en CINÉPOLIS, el 14\% en TELMEX, 6\% MAZAPANES LA ROSA, 13\% la marca SUEROX, 5\% SALSA HUNT. En la tabla 1 , se muestran los productos y marcas con el distintivo de ESR. 
Imagen 13 .Productos/Marcas, con el distintivo de ESR

\section{¿ Recuerda haber visto este logotipo en alguno (s) de los siguientes productos y /o servicios, marque todos los que recuerde?}

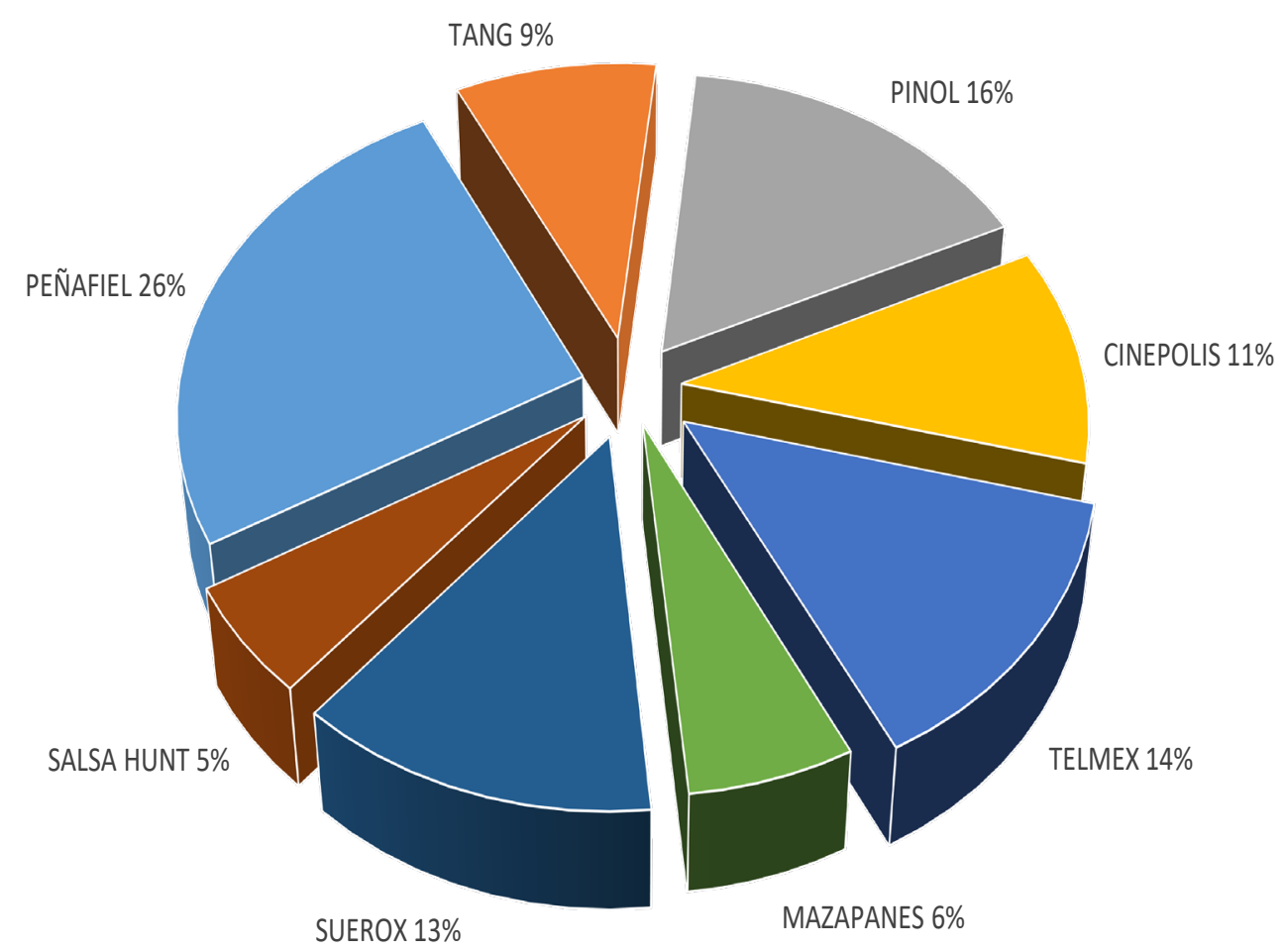

Fuente: Elaboración propia. México. Marzo, 2021.

Tabla 1. Productos/marcas con el distintivo de ESR, en su etiqueta Productos con el distintivo ESR PEÑAFIEL TANG
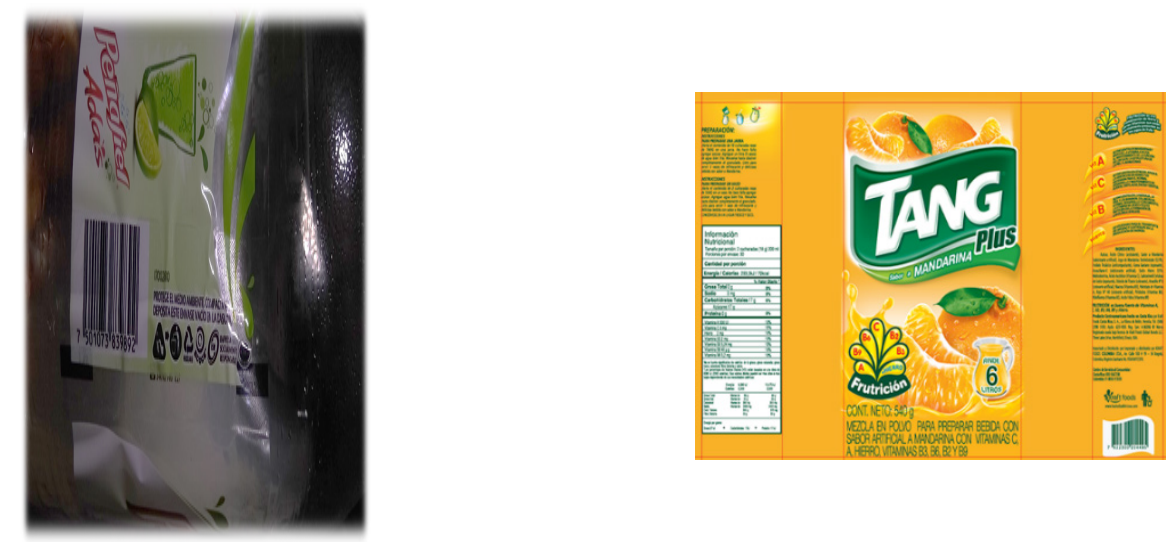


\section{PINOL}

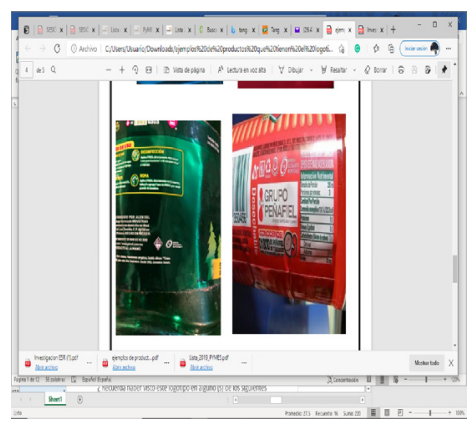

TELMEX

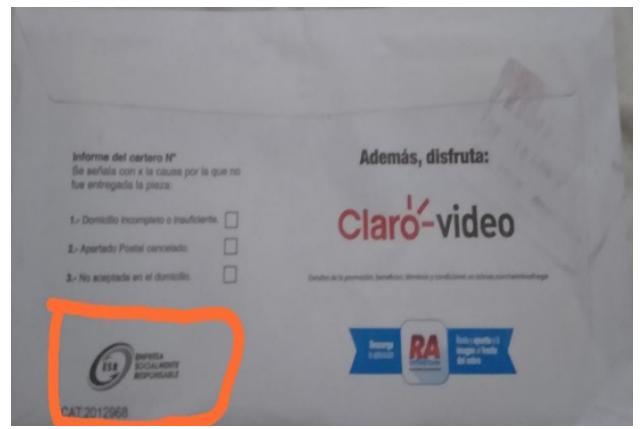

SUEROX

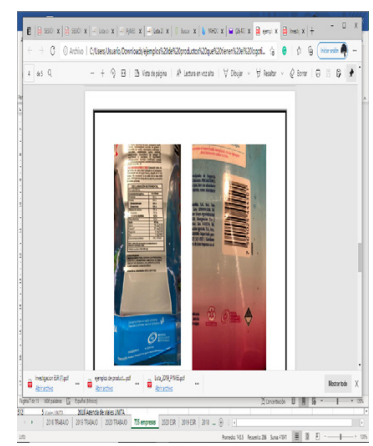

CINÉPOLIS

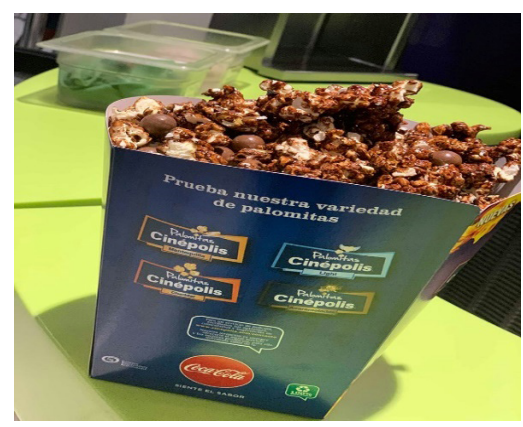

MAZAPANES LA ROSA

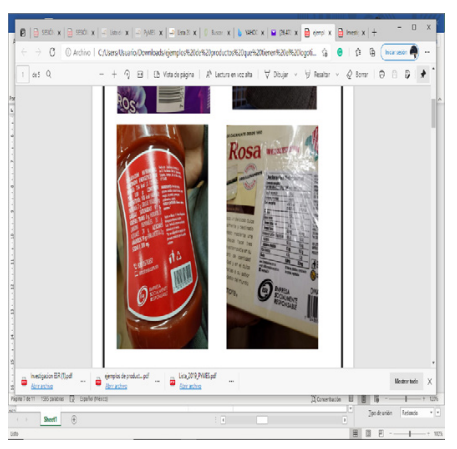

SALSA HUNT

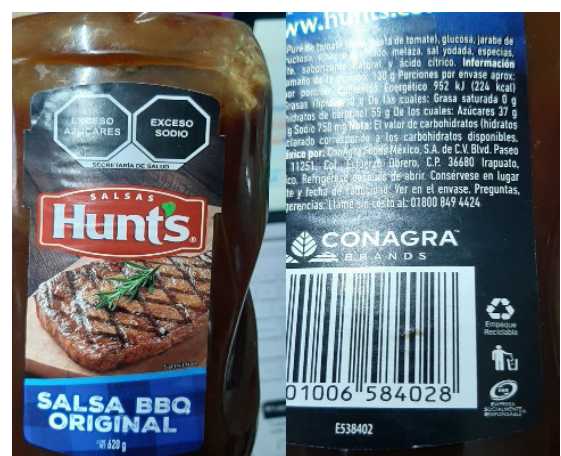

Fuente: Fotografías de productos PEÑAFIEL, TANG, PINOL, CINÉPOLIS, TELMEX, MAZAPANES LA ROSA, SUEROX, SALSA HUNT, para mostrar el distintivo de ESR

\section{Empresas con el Distintivo ESR 2018, 2019, 2020}

En la siguiente tabla se muestra el número total de empresas que han logrado obtener el distintivo de ESR, por primera vez, siendo un total de 735 empresas, también se observan aquellas que ya lo han logrado obtener hasta por 15 años, también se presentan las entidades u organismos promotores de la RSE, para el año 2020. 


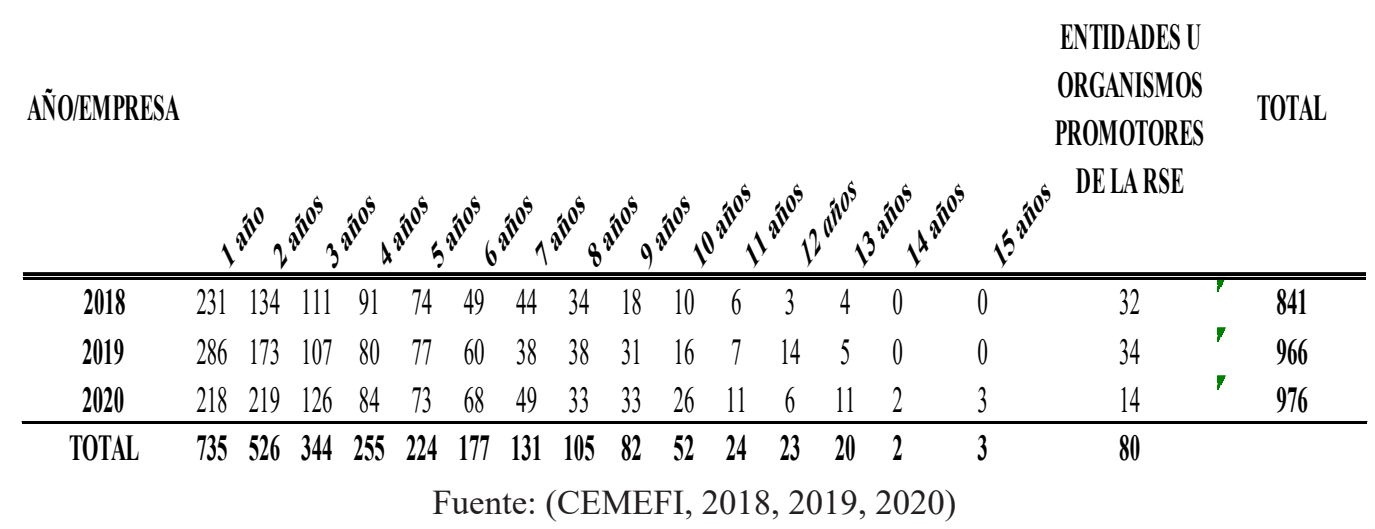

Se presenta en este trabajo los años 2018, 2019 y 2020, siendo el tamaño de empresas, por número de trabajadores, la ubicación, el sector económico y si ostentan el distintivo de ESR en su página de Internet.

Tabla 3. Empresas Pymes, para los años 2018, 2019 y 2020

\begin{tabular}{cc} 
AÑO/EMPRESA & 1 año \\
\hline \hline $\mathbf{2 0 1 8}$ & 231 \\
$\mathbf{2 0 1 9}$ & 286 \\
$\mathbf{2 0 2 0}$ & 218 \\
\hline TOTAL & $\mathbf{7 3 5}$
\end{tabular}

Fuente: (CEMEFI, 2018, 2019, 2020)

\section{Empresas Pymes ganadoras con el distintivo ESR en el año 2020}

Para el año 2020, se muestran los resultados de las empresas que obtuvieron el distintivo ESR.

En la imagen 14, están los resultados de la investigación, respecto a que empresas muestran el distintivo de ESR en sus páginas de Internet, las que lograron obtener en el año 2020. El 63\% de las empresas no muestra todavía el distintivo ESR, el $35 \%$ si lo muestran y el $2 \%$ no se encontró información. En la imagen 15, se muestra el tamaño de empresas que obtuvieron el distintivo de ESR, en el año 2020, encontrando que el $17 \%$ son empresas de tamaño micro, $34 \%$ son pequeñas y $20 \%$ medianas, aunque el $29 \%$ no se encontró el número de trabajadores, por lo que no se pudo determinar su tamaño. 
Imagen 14. 2020, Empresas que tienen el distintivo de ESR en su página de Internet

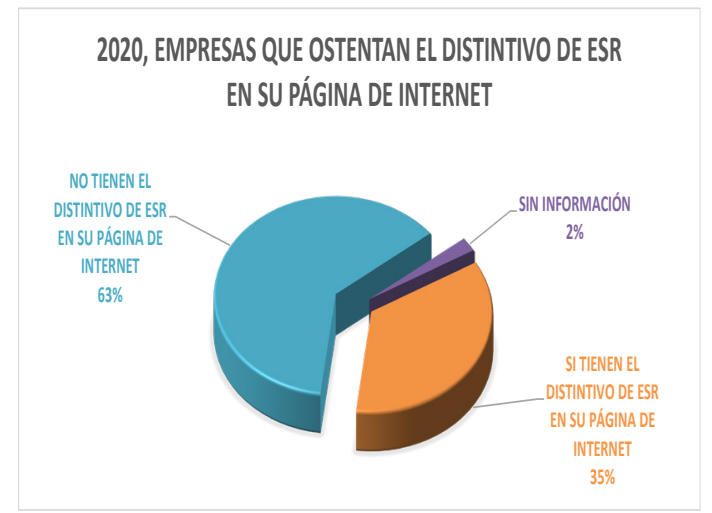

Fuente: Elaboración propia con datos de CEMEFI, 2020. México. Marzo, 2021.
Imagen 15. 2020, Tamaño de empresas que obtuvieron el distintivo de ESR

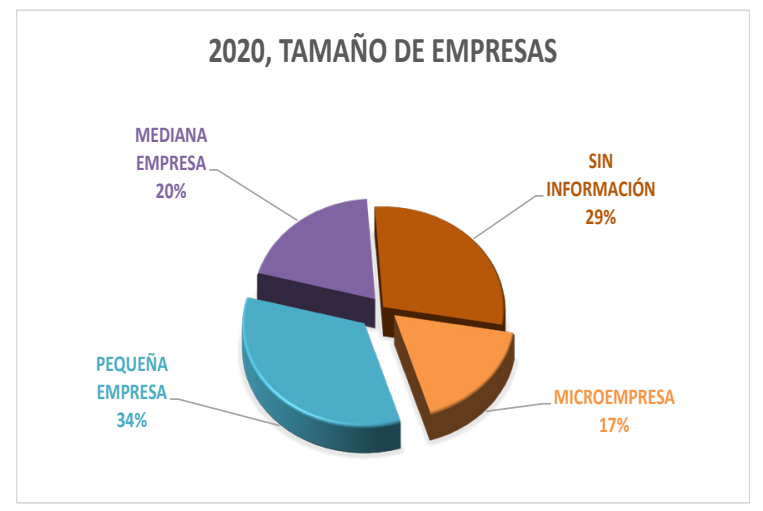

Fuente: Elaboración propia con datos de CEMEFI, 2020. México. Marzo, 2021.

En la imagen 16, se muestra la ubicación de las empresas, siendo el 25\% de la Ciudad de México y el 21\% del Estado de Guanajuato y el 51\% de diferentes Estados de la República Mexicana. En la imagen 17, se muestra el sector económico al que pertenecen las empresas, siendo principalmente del sector servicios $67 \%$ y el $32 \%$ del sector productivo.

Imagen 16. 2020, ubicación de las empresas, que obtuvieron el distintivo de ESR

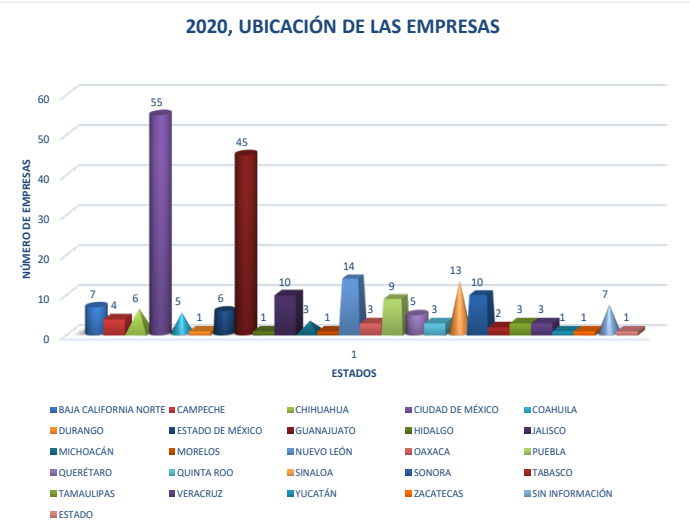

Fuente: Elaboración propia con datos de CEMEFI, 2020. México. Marzo, 2021.
Imagen 17. 2020, sector económico de las empresas que obtuvieron el distintivo de ESR 2020, EMPRESAS SEGÚN ACTIVIDAD ECONÓMICA

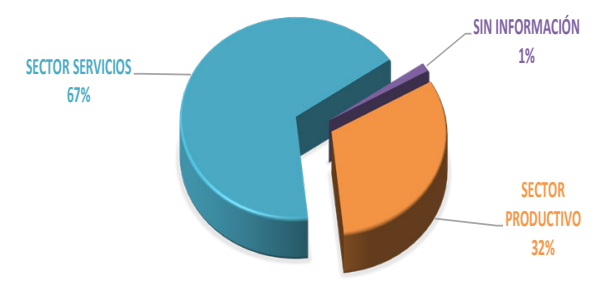

Fuente: Elaboración propia con datos de CEMEFI, 2020. México. Marzo, 2021.

En la tabla 4, están las imágenes de algunas empresas que se seleccionaron para mostrar que efectivamente presentan en sus páginas de Internet el distintivo de ESR, que lo obtuvieron en el año 2020. 
Tabla 4. Algunos ejemplos de Empresas que presentan en sus páginas de Internet el distintivo de ESR 2020

Aceitera Mevi

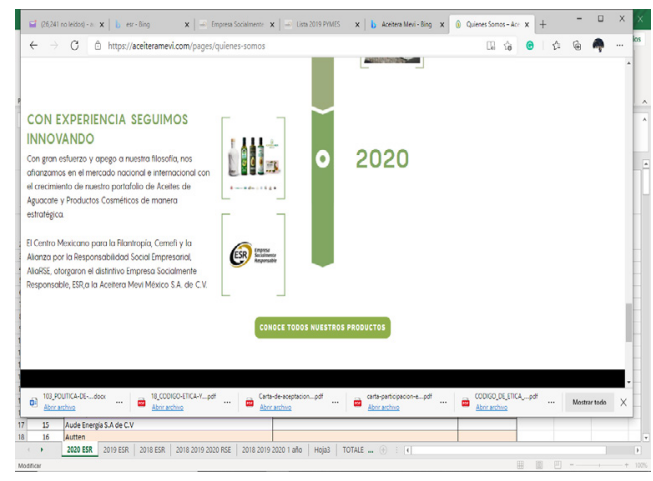

Aire Proyectos del Golfo

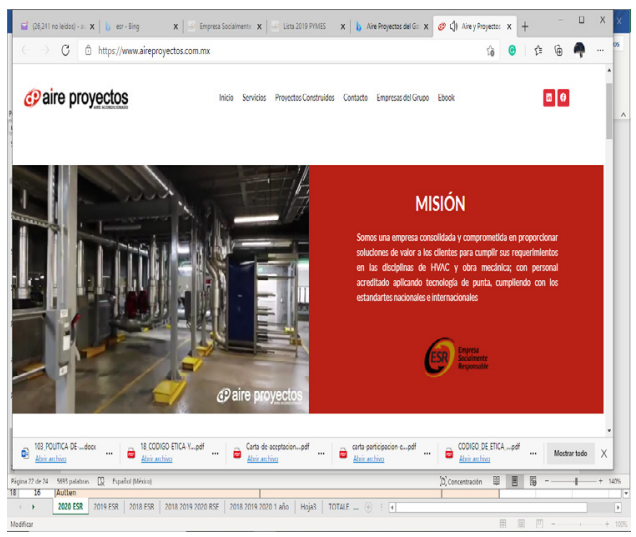

Grupo ISEA

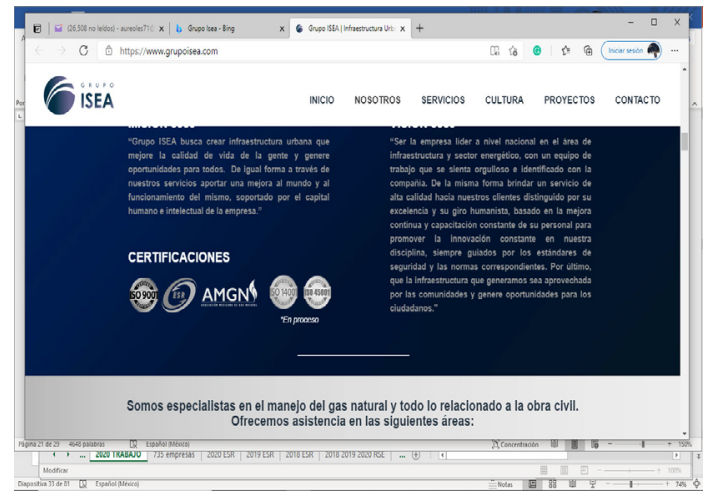

Promogex, S.A. de C.V.

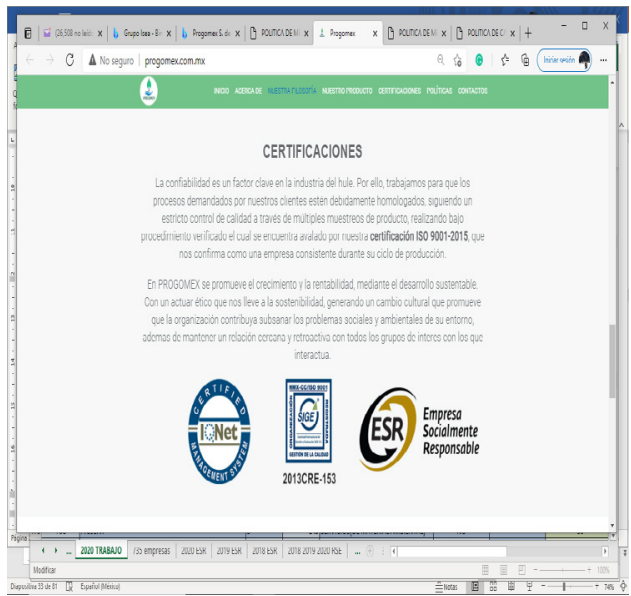

Fuente: Elaboración propia con datos de las páginas de Internet de las empresas consultadas.

\section{Empresas Pymes ganadoras con el distintivo ESR en el año 2019}

Para el año 2019, se muestra en la imagen 18, las empresas que obtuvieron el distintivo de ESR durante ese año se encontraron que solamente el $41 \%$ ostenta el distintivo en su página de internet, mientras que el 55\% todavía no lo presentan. En la imagen 19 se tiene la actividad económica, el 69\% de las empresas tienen como actividad económica el sector servicios y el 28\% son del sector productivo.

Imagen 18. 2019, empresas que ostentan el distintivo ESR en su página de Internet

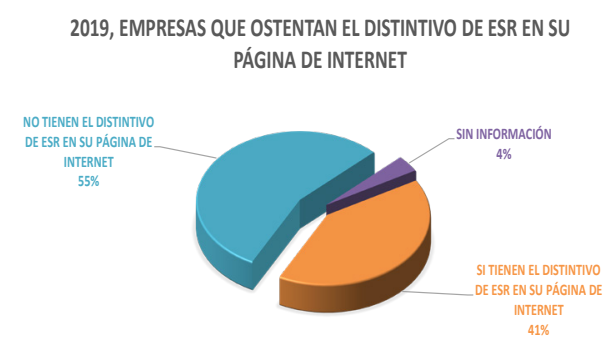

Fuente: Elaboración propia con datos de CEMEFI, 2019. México. Marzo, 2021.
Imagen 19. 2019, empresas según actividad económica

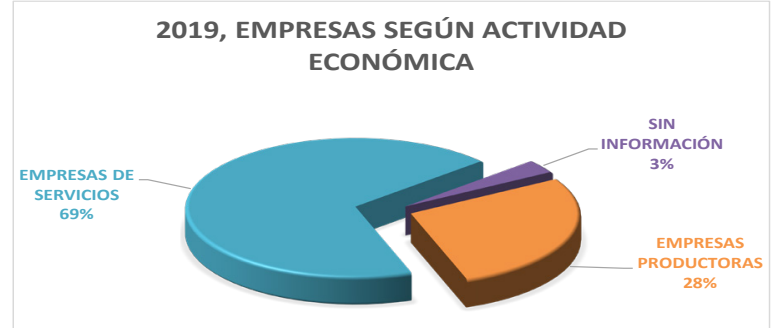

Fuente: Elaboración propia con datos de CEMEFI, 2019. México. Marzo, 2021. 
En la imagen 20, está la ubicación de las empresas que obtuvieron el distintivo de ESR para el año 2019, el 24\% se ubican en la Ciudad de México, el 12\% en Jalisco, el 7\% en el Estado de México, el $5 \%$ en Guanajuato y el restante $38 \%$ en otros estados, mientras que el 14\% no se encontró de qué lugar provenían. En la imagen 21, se muestra la ubicación de las empresas de los diferentes países de Latinoamérica, provenientes de Argentina, Colombia, Costa Rica, El Salvador, Guatemala, Honduras, Panamá y Perú.

Imagen 20. 2019, Ubicación de las empresas, por estados de la República Mexicana

\section{9, UBICACIÓN DE LAS EMPRESAS}

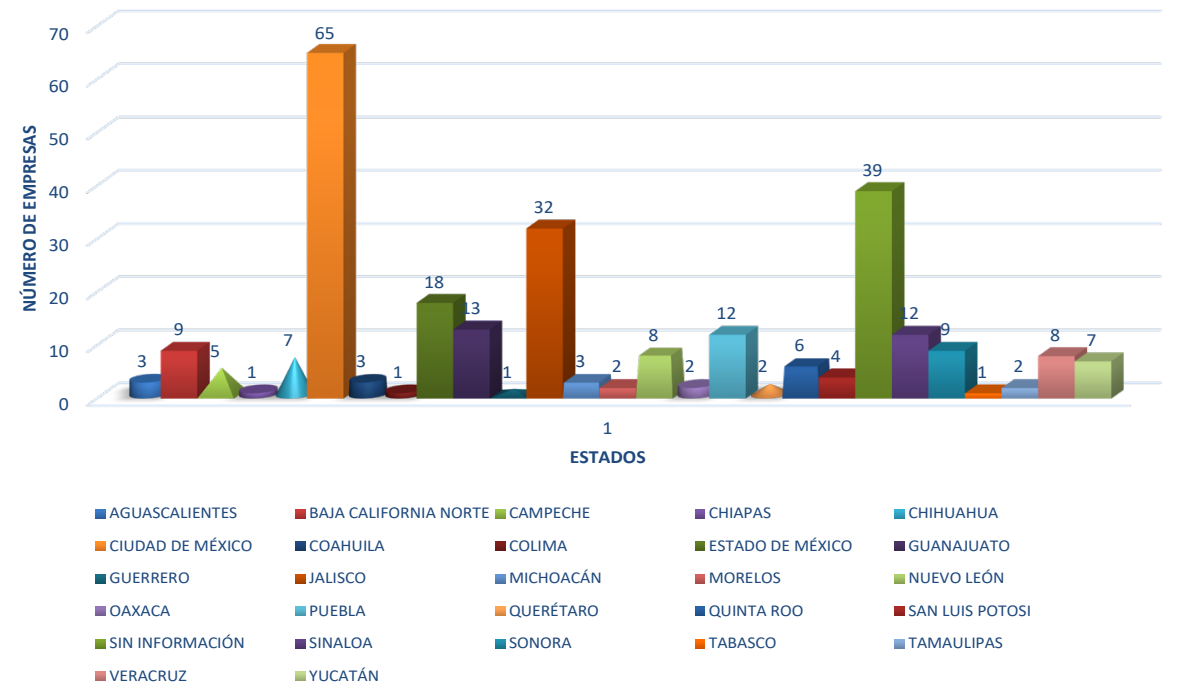

Fuente: Elaboración propia con datos de CEMEFI, 2019. México. Marzo, 2021.

Imagen 21. 2019, Ubicación de las empresas, por países de Latinoamérica

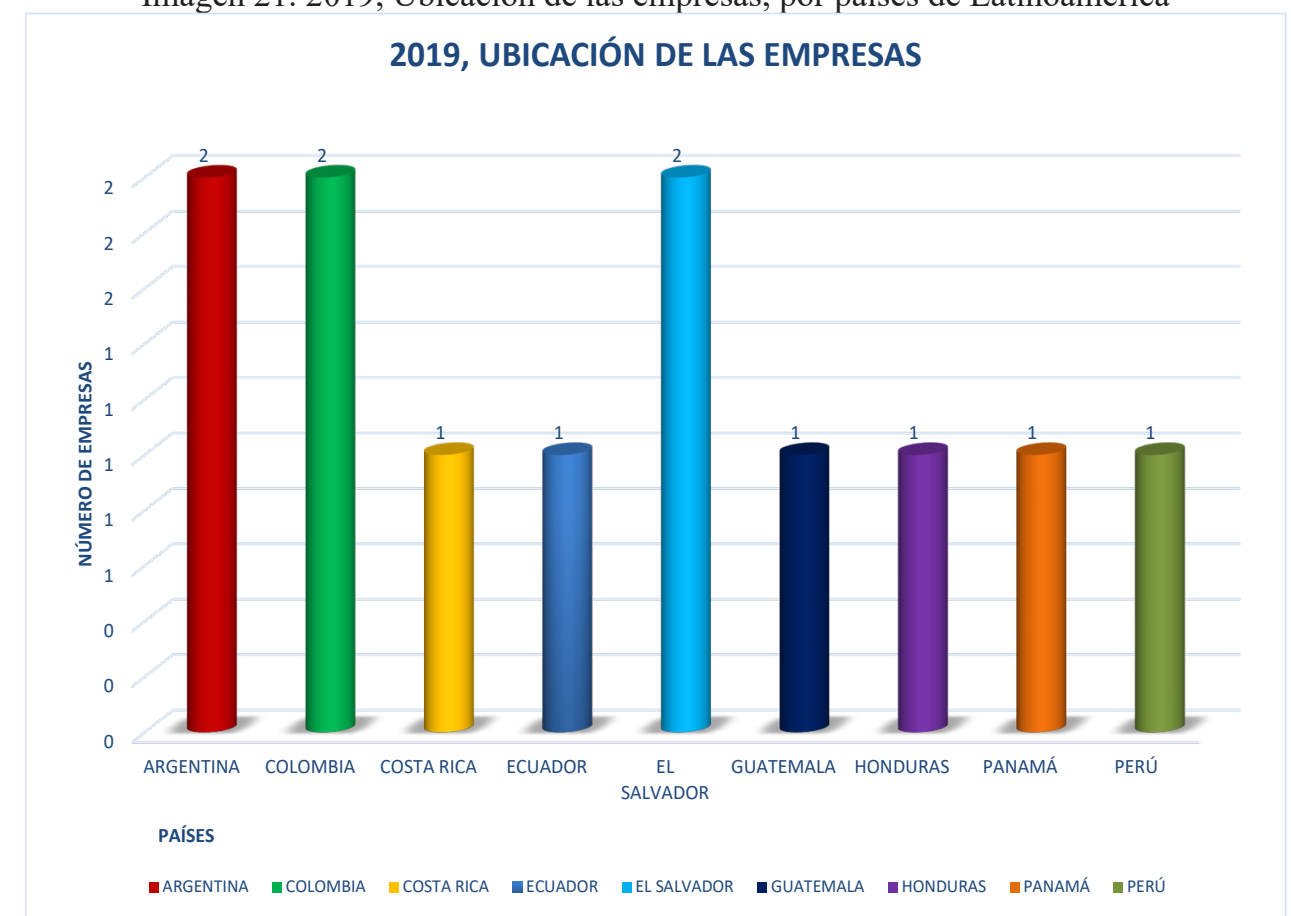

Fuente: Elaboración propia con datos de CEMEFI, 2019. México. Marzo, 2021. 
En la tabla 5 se encuentran algunos ejemplos de empresas que muestran en sus páginas de Internet el distintivo de ESR, que obtuvieron en el año 2019.

Tabla 5. Algunos ejemplos de Empresas que presentan en sus páginas de Internet el distintivo de ESR 2019

YPM Consultores, S.C.

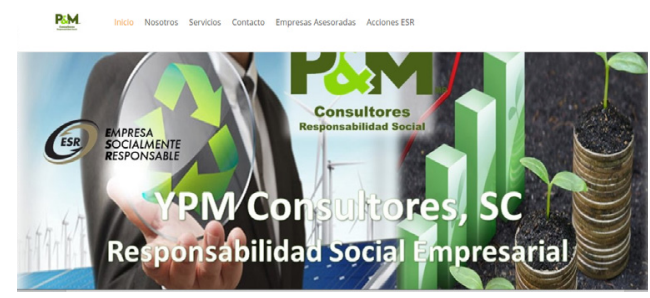

SMB RURAL
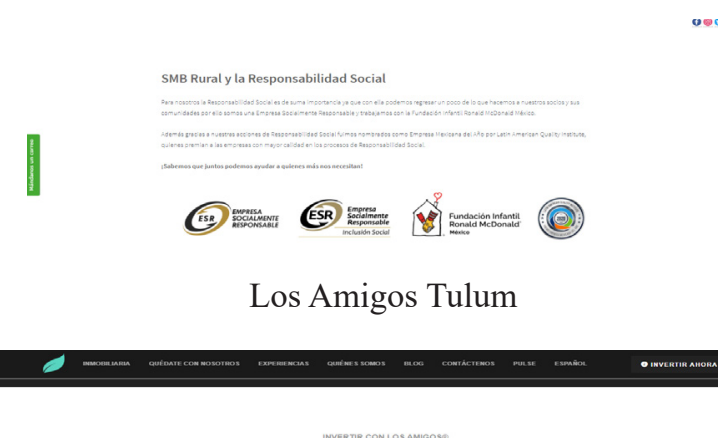

- muvertimanoan

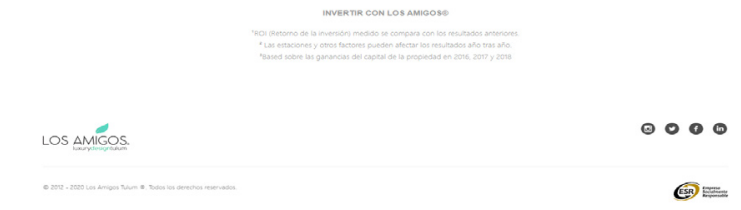

Hola Trabajo, S.A de C.V.

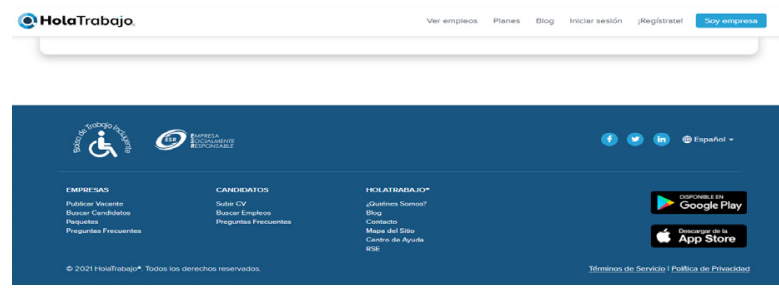

Fuente: Elaboración propia con datos de las empresas que se mencionan.
Terán Rojas \& Associates

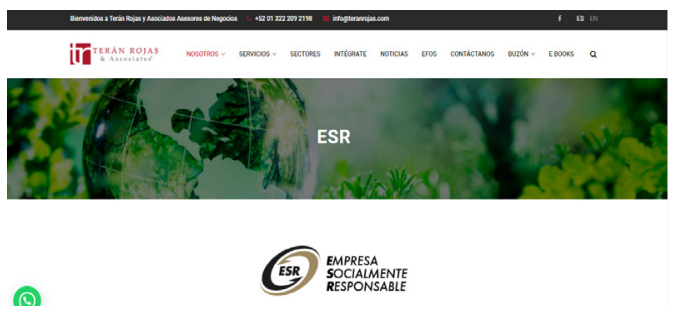

PURIFIKA

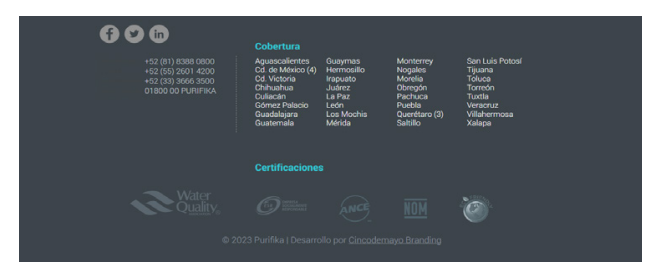

LEEX Lenguas Extranjeras

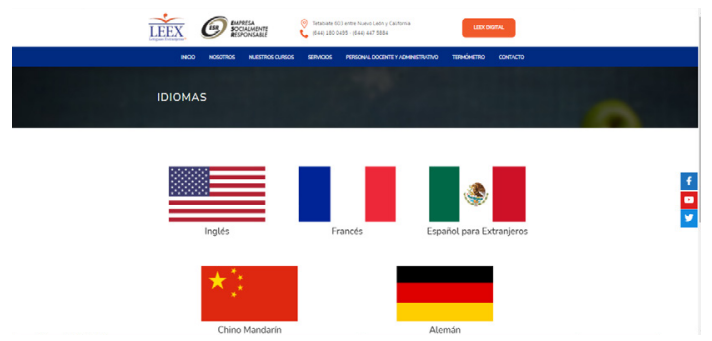

Fluidos Mayanstar

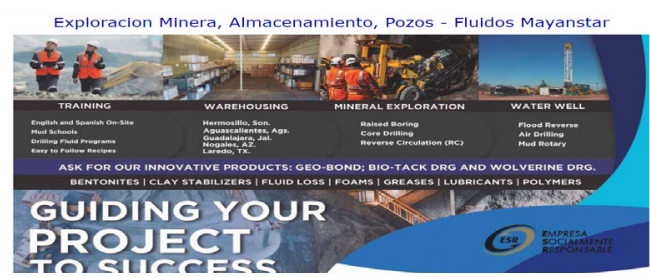

\section{Empresas Pymes ganadoras con el distintivo ESR en el año 2018}

En la imagen 22 se muestra que las empresas Pymes que obtuvieron el distintivo de ESR en el año 2018, solamente el 56\% si lo tienen en su página de Internet y el 44\% no lo tienen. En la imagen 23 , está el sector económico al que pertenecen, el 67\% al sector servicios y el 32\% al sector productivo. 
Imagen 22. Empresas Pymes que ostentan el distintivo de Imagen 23. Empresas Pymes, según actividad económica, ESR, que lo obtuvieron en el año 2018 2018

\section{8, EMPRESAS QUE OSTENTAN EL DISTINTIVO DE ESR EN \\ SU PÁGINA DE INTERNET}

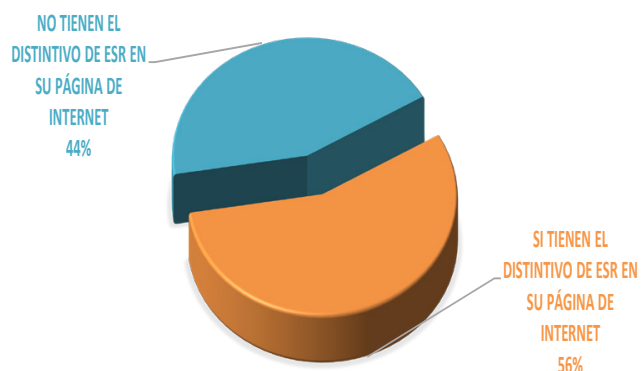

Fuente: Elaboración propia con datos de CEMEFI, 2018. México. Marzo, 2021.

\section{8, EMPRESAS SEGUUN ACTIVIDAD ECONÓNICA}

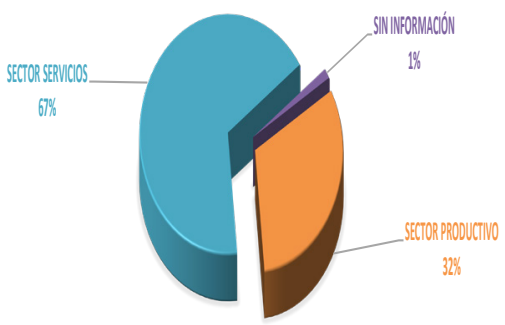

Fuente: Elaboración propia con datos de CEMEFI, 2018. México. Marzo, 2021.

En la siguiente imagen 24 está la ubicación de las empresas, que en el año 2018 obtuvieron el distintivo de ESR, el $25 \%$ se ubican en la Ciudad de México, el 14\% en Jalisco, el 10\% en Sinaloa, $6 \%$ en Puebla, $6 \%$ en Nuevo León, $6 \%$ en el Estado de México y el 22\% del resto de los estados que se muestran. Para este año solamente se encontraron 2 empresas del país de Costa Rica.

Imagen 24. Ubicación de las empresas del año 2018

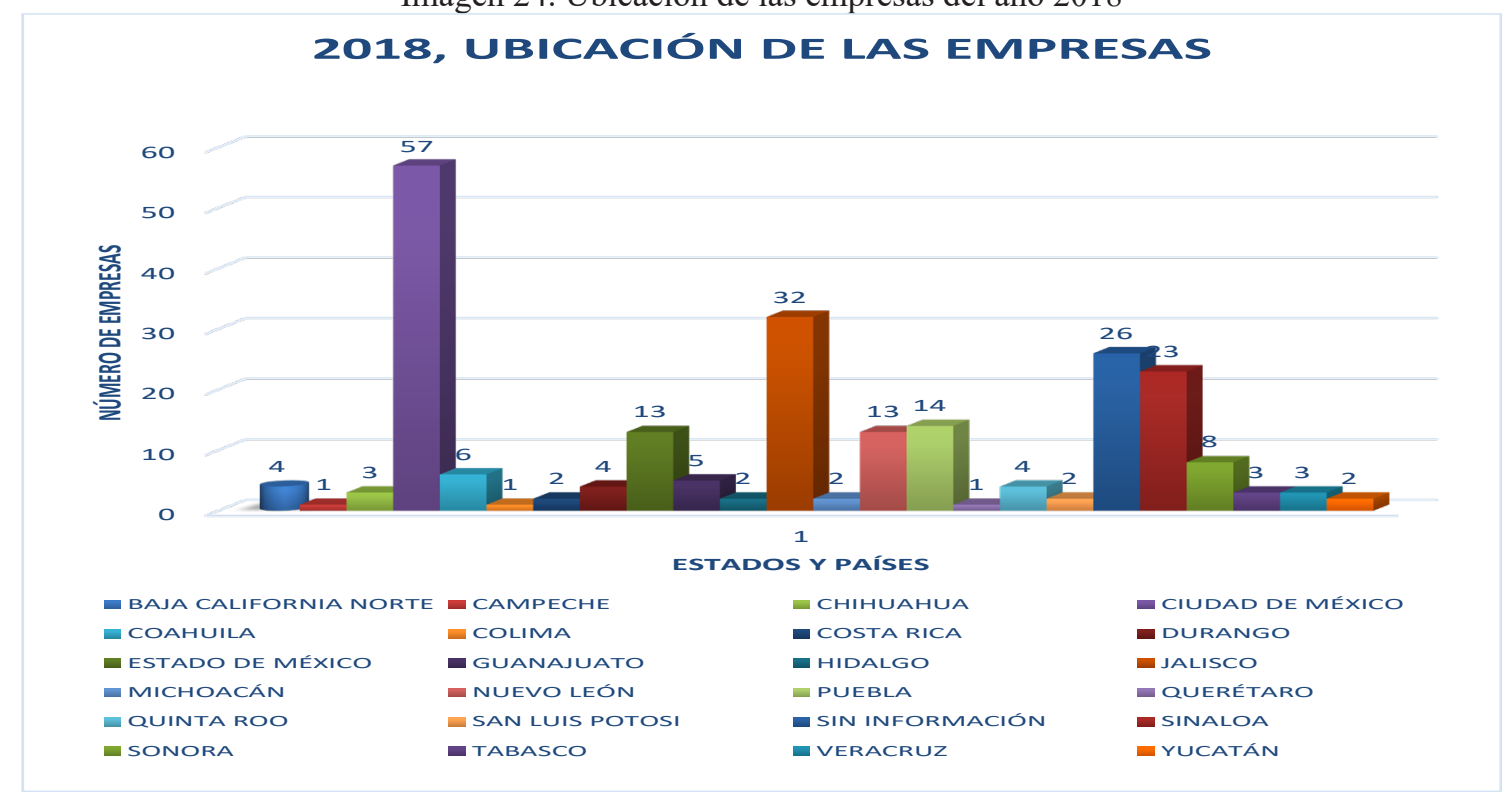

Fuente: Elaboración propia, con datos de CEMEFI 2018. México. Marzo, 2021.

En la tabla 6, se muestran algunos ejemplos de empresas que obtuvieron el distinto de ESR, en el año 2018, y que lo muestran en su página de Internet. 
Tabla 6. Algunos ejemplos de Empresas que presentan en sus páginas de Internet el distintivo de ESR 2018

AE Andamios Express

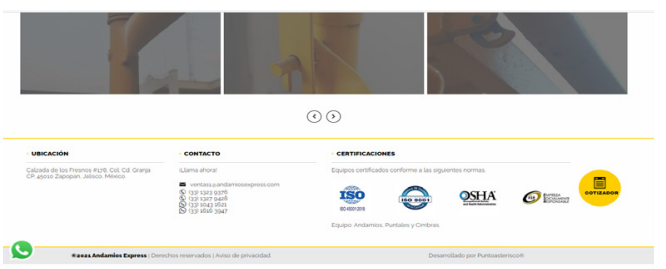

Agrorgánicos Nacionales

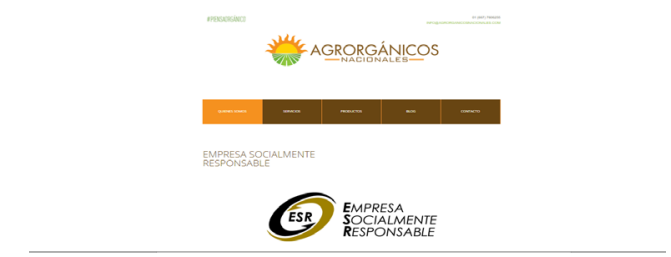

Americaasia

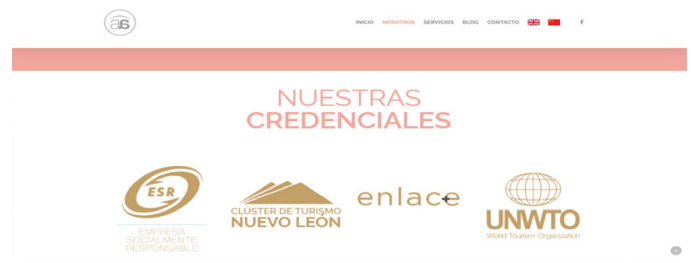

Anaerobia S.A. de C.V.

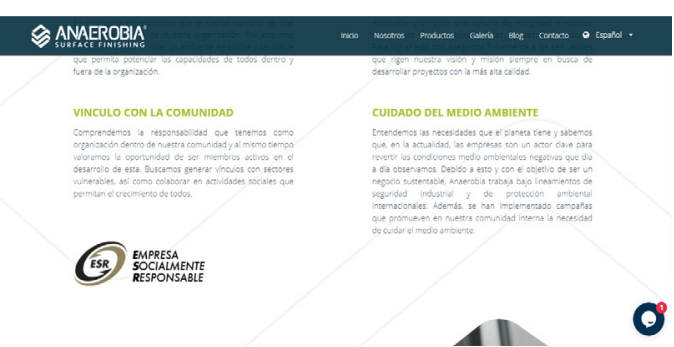

Agrícola Am Mex S de RL de C.V.

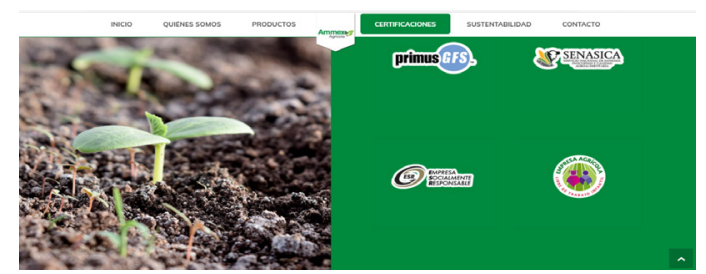

Agua y saneamiento ambiental S.A. de C.V.

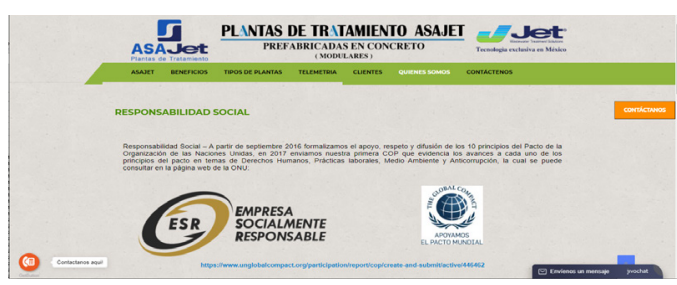

3R Respuesta rápida en reclutamiento

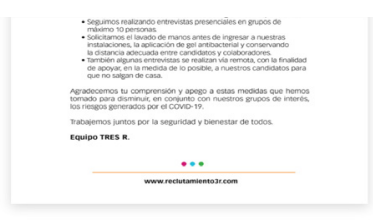

(2)

UPL CONSTA RICA S.A. DE C.V.

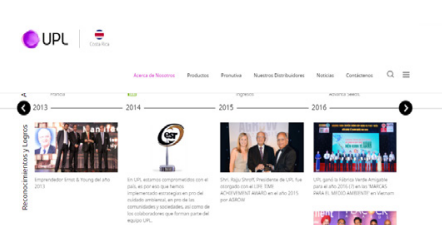

8.

Fuente: Elaboración propia con datos de las empresas que se mencionan.

La Responsabilidad Social Empresarial (RSE)

Finalmente, en las tablas 7 y 8 se encuentran las 80 entidades y organismos promotores de la RSE, para los años de estudio 2018, fueron un total de 32, para el año 2019, fueron consideras 34 y para el año 2020, solamente 14 .

Tabla 7. Entidades u organismo promotores de la RSE, 2018, 2019 y 2020

ENTIDADES U ORGANISMOS PROMOTORES DE LA RSE

\begin{tabular}{|c|c|c|}
\hline 2018 & 2019 & 2020 \\
\hline 32 & 34 & 14 \\
\hline
\end{tabular}

Fuente: Elaboración propia con datos de CEMEFI, 2018, 2019 y 2020. 
Tabla 8. Entidades u organismos promotores de la RSE, 2018, 2019 y 2020

\section{ENTIDADES U ORGANISMOS PROMOTORES DE LA RSE}

\begin{tabular}{|c|c|c|}
\hline 2018 & 2019 & 2020 \\
\hline 32 & 34 & 14 \\
\hline CAINTRA Nuevo León & Ayuntamiento de Mérida & Cámara nacional de comercio servicios y turismo de guadalajara \\
\hline Cámara Mexicana de la Industria de la Construcción & Cámara Mexicana de la Industria de la contrucción Delegación Jalisco & Canacintra hermosillo \\
\hline Cámara Mexicana de la Industria de la Construcción Delegación Colima & Cámara Mexicana de la Industria de la contrucción Delegación Jalisco & Centro de ciencias de sinaloa \\
\hline Cámara Mexicana de la Industria de la Construcción Delegación Jalisco & Cámara Nacional de Comercio Servicios y Turismo de Guadalajara & Centro empresarial de jalisco $S, P$ \\
\hline Cámara Nacional de Comercio Servicios y Turismo de Guadalajara & Camara Nacional de Empresas de Consultoría & CICEG \\
\hline Cámara Nacional de Empresas de Consultoría & Cámara Nacional de la Industria Tequilera & Cúster minero de guerrero \\
\hline CANACINTRA Delegación Guasave & CANACINTRA Delegación Guasave & COBAES \\
\hline CANAJAD & CANACO SEBYTUR DELÉVORA & Comisión estatal de aguas \\
\hline CANIPEC & CANTRA Nuevo León & Consejo coordinador empresarial de guasave \\
\hline Centro de Ciencias de Sinaloa & CANIPEC & Municipio de irapuato, GTO \\
\hline Centro empresarial de Jalisco S.P & Centro de Ciencias de Sinaloa & Nido social \\
\hline CICEG & Centro Empresarial de Jalisco S.P & Servicios de agua y drenaje de monterry I.D.P \\
\hline Clúster minero de sonora A.C & CICEG & Universidad autónoma de sinaloa \\
\hline CMIC Delegación Sonora & CINTERMEX & USEM Puebla \\
\hline CMIC Hídalgo & Clúster Minero de Guerrero A.C & \\
\hline COBAES & Clúster Minero de Sonora & \\
\hline CODESIN Zona Centro Norte & CMIC Delegación Sonora & \\
\hline CODESIN Zona Norta & COBAES & \\
\hline Condeferación de Cámaras Industriales de los Estados Unidos Méxicanos & CODESIN Zona Norte & \\
\hline Consejo Coordinador Empresarial de Campeche & Colegio de Ingenieros Civiles del Estado de Jalisco A.C & \\
\hline Consejo Coordinador Empresarial de Puebla & Consejo Coordinador Empresarial de Campeche A.C & \\
\hline FOVISSSTE & Consejo Coordinador Empresarial de Puebla & \\
\hline Instituto M.I.A & Consejo de la Comunicación A.C & \\
\hline Municipio de Nicolás Romero & FOVISSSTE & \\
\hline Registro Único de Vivienda & Fundación Down de Puebla A.C & \\
\hline Secretaría de Turismo del Estado de México & Instituto M.I.A & \\
\hline Servicio de Administración y Enajenación de Bienes & Instituto Tecnológico Superior de Guasave & \\
\hline Servicios de Agua y Drenaje de Monterrey I.D.P & Municipio de Irapuato, Guanajuato & \\
\hline Universidad Autónoma de Coahuila & Philip Morris Mexico & \\
\hline Universidad Autónoma de Sinaloa & Servicios de Agua y Drenaje de Monterrey I.P.D & \\
\hline Universidad Politécnica de Sinaloa & Universidad Autónoma de Coahuila & \\
\hline \multirow[t]{3}{*}{ Universidad Tecnológica de San Juan del Río } & Universidad Autónoma de Sinaloa & \\
\hline & Universidad Politécnica de Sinaloa & \\
\hline & Universidad Tecnológica de San Juan del Río & \\
\hline
\end{tabular}

Fuente: Elaboración propia con datos de CEMEFI, 2018, 2019 y 2020

En la tabla 9, se muestran tres empresas como ejemplos de empresas que lograron obtener el distintivo de ESR, mencionado cuales son los logros por lo que lo obtiene, como son sus políticas del medio ambiente, la igualdad de trato, las medidas de anticorrupción, la calidad de vida de sus trabajadores, el cuidado de sus proveedores, la comunidad, el respeto a los derechos humanos, su ética empresarial, respetando su código de ética, y la responsabilidad social. 
Tabla 9. Ejemplos de Empresas que obtuvieron el distintivo de RSE, en los años 2018, 2019 y 2020

HOLA TRABAJO

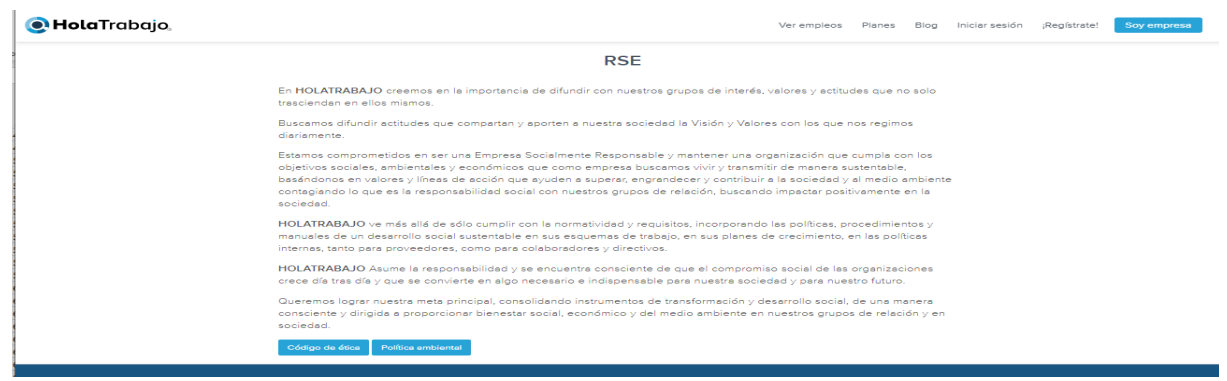

310MED

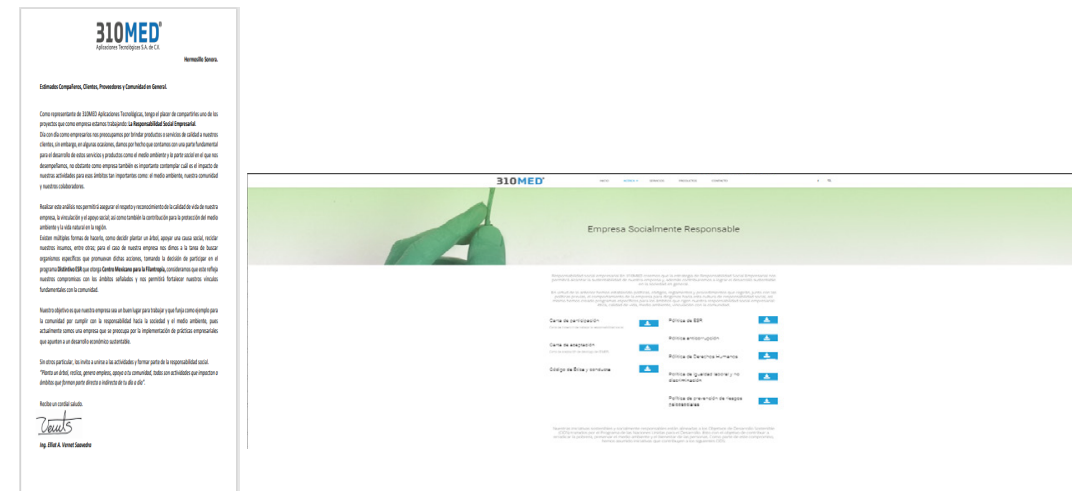

PROGOMEX, S.A. DE C.V.

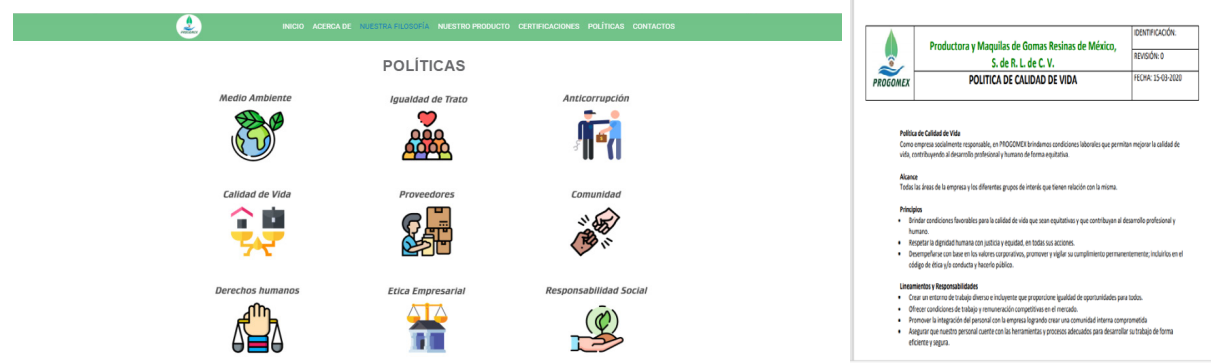

Fuente: Elaboración propia con datos de las empresas Hola Trabajo, 310MED y PROGOMEX, S.A. DE C.V.

\section{CONCLUSIONES Y FUTURAS LÍNEAS DE INVESTIGACIÓN}

Se menciona la importancia de conocer las empresas de tamaño micro, pequeñas y medianas que han logrado obtener el distintivo de ESR, es posible como línea futura hacer una investigación para conocer con mayor detalle estas empresas, respecto a los beneficios que logran por tener este distintivo, preguntarse que han ganado y los beneficios, porqué siendo una participación voluntaria, las empresas se encuentran interesadas en participar y poder ganar ese distintivo. A los consumidores que se les preguntó sobre el tema, perciben y opinan que es una ventaja para las empresas y que para ellos como consumidores consideran que están adquiriendo un buen producto, que si una marca trae ese distintivo o logotipo, les permite tener confianza en lo que están comprando, porque al consumirlo están adquiriendo un producto de calidad y que se preocupa por el cuidado del medio ambiente.

Pero también, se encontró con la realización de esta investigación, que es necesario proporcionar más información a los consumidores con cada uno de los logotipos que los productos y las marcas tienen, que significa cada uno de ellos, responder a la pregunta ¿qué significan cada uno de los logotipos o 
distintivos que se encuentran en las etiquetas de los productos? ¿qué beneficios le pueden traer al consumidor' ¿porqué le deben interesar?

En la siguiente investigación se abordará el tema respecto al impacto de los cinco sellos que ahora con la norma 050, se están colocando en las etiquetas de los productos.

Por supuesto que todavía hay preguntas que responder, respecto a los beneficios a la sociedad con respecto a estas empresas, entidades y organismos que logran obtiener el distinto de Responsabilidd Social Empresarial (RSE), se debe investigar, para que la población en general, también este más informada y pueda elegir de una forma más consciente los productos que debe comprar y consumir, que en realidad las empresas estén evitando en su producción, el daño al medio ambiente, que cuiden a sus trabajadores, que haya más responsabilidad hacia adentro de las empresas, por lo que quedan pendientes algunos estudios de endomarketing o marketing interno en algunas de estas 735 empresas que se investigaron y de los 80 organismos y entidades promotoras de la RSE, para dar respuestas a la sociedad.

\section{REFERENCIAS}

1. Aaker, D., \& Kumar, V. \&. (2010). Investigación de Mercados. México: Limusa.

2. Alimentos, R. S. (2021). Obtenido de (http://web.minsal.cl/reglamento-sanitariode-los-alimentos/)

3. CEMEFI. (2018, 2019, 2020). Obtenido de https://www.cemefi.org/esr/

4. CEMEFI. (2019). Obtenido de https://www.cemefi.org/esr/images/stories/pdf/esr/concepto_esr. pdf

5. EXPONEWS. (9 de agosto de 2010). Expok, Comunicación de RSE y SustentabilidadLas 10 diferencias entre Responsabilidad Social y Marketing Social. Obtenido de Expok, Comunicación de RSE y Sustentabilidad- Lashttp://www.expoknews.com/las10diferenciasentre responsabilidadsocialymarketingsocial

6. FCEE. (Noviembre de 2014). Responsabilidad Social Empresarial. Obtenido de http://www. rsexunta.es

7. Fischer, F. (2017). Mercadotecnia sustentable y su aplicación en México y Latinoamérica. México: UNAM-FCA.

8. Fischer, L., \& Espejo, C. J. (2017). Mercadotecnia. México: Mc Graw Hill.

9. INDAP. (2021). indap.gob.cl. Obtenido de http://www.indap.gob.cl/docs/default-source/defaultdocument-library/manual-de-etiquetado-minsal-vf.pdf?sfvrsn=0

10. INEGI. (2021). INEGI. Obtenido de https://www.inegi.org.mx/programas/ccpv/2020/default.html

11. Kotler, P. \&. (2017). Marketing. México: Pearson.

12. Maram, L. (mayo de 2011). La diferencia entre marketing social y responsabilidad social. Revista Equilibrio. Obtenido de https://www.luismaram.com/la-diferencia-entre-marketing-social-yresponsabilidad-social/

13. NOM. (2004). Obtenido de http://www.ordenjuridico.gob.mx/Federal/PE/APF/APC/SE/Normas/ Oficiales/NOM-050-SCFI-2004.pdf

14. Peñaloza, M. (enero-junio de 2005). El Mix de Marketing:Una herramienta para servir al cliente. . Actualidad Contable Faces, 8(10), 71-81. Obtenido de https://www.redalyc.org/articulo. oa? id $=25701007$

15. RAE. (15 de agosto de 2021). Real Academia Españolaaa. Obtenido de https://dle.rae.es/

16. Sampieri, H., Méndez, V., \& Mendoza, T. \&. (2017). Fundamentos de investigación. México: Mc Graw Hill.

17. Stanley. (2021).ÉTICA Y RSE. MARKETING.PDF. Obtenido de https://rephip.unr.edu.ar/bitstream/ handle $/ 2133 / 7441 /$ Stanley, $\% 20$ etica $\% 20 y \% 20$ rse $\% 20$ marketing.pdf?sequence=3\&isAllowed=y 